\title{
Application of DNA-Nanosensor for Environmental Monitoring: Recent Advances and Perspectives
}

\author{
Vineet Kumar ${ }^{1}$ (D) Praveen Guleria ${ }^{2}$ \\ Accepted: 4 October 2020 \\ (C) Springer Nature Switzerland AG 2020
}

\begin{abstract}
Purpose of Review Environmental pollutants are threat to human beings. Pollutants can lead to human health and environment hazards. The purpose of this review is to summarize the work done on detection of environmental pollutants using DNA nanosensors and challenges in the areas that can be focused for safe environment.

Recent Findings Most of the DNA-based nanosensors designed so far use DNA as recognition element. ssDNA, dsDNA, complementary mismatched DNA, aptamers, and G-quadruplex DNA are commonly used as probes in nanosensors. More and more DNA sequences are being designed that can specifically detect various pollutants even simultaneously in complex milk, wastewater, soil, blood, tap water, river, and pond water samples. The feasibility of direct detection, ease of designing, and analysis makes DNA nanosensors fit for future point-of-care applications.

Summary DNA nanosensors are easy to design and have good sensitivity. DNA component and nanomaterials can be designed in a controlled manner to detect various environmental pollutants. This review identifies the recent advances in DNA nanosensor designing and opportunities available to design nanosensors for unexplored pathogens, antibiotics, pesticides, GMO, heavy metals, and other toxic pollutant.
\end{abstract}

Keywords Pollutant $\cdot$ Pathogen $\cdot$ GMO $\cdot$ Antibiotic $\cdot$ Heavy metals $\cdot$ Pesticide

\section{Introduction}

Human activities in twentieth century have been associated with undue alteration in the existing environmental conditions with a tendency of over exploitation of natural resources unlike other animals. Civilization, increasing population followed by industrialization has set a race for the production and usage of man-made resources with a simultaneous depletion of natural resources. There is an increased demand for food, daily essential amenities that in turn has raised concern regarding human health. Engineering in the last 2-3 decades has

This article is part of the Topical Collection on Biology and Pollution

Vineet Kumar

vineetkumar22@gmail.com

1 Department of Biotechnology, School of Bioengineering and Biosciences, Lovely Professional University (LPU), Jalandhar Delhi G.T. Road, Phagwara, Punjab 144411, India

2 Department of Biotechnology, Faculty of Life Sciences, DAV University, Jalandhar, Punjab 144012, India focused over designing of new chemicals and materials with never-known properties. These man-made resources do not have natural fate and pile up in the environment. Most of these man-made resources are serious threat to human health and environment [1]. Pollutants may be present in air, water, food, and day-to-day consumer products. Contaminated air, water, soil, and daily use materials directly affect human health. Pollution claimed approximately 9 million deaths globally in 2015. The causalities are three times higher than deaths from AIDS, tuberculosis, and malaria. Pollution negatively affects every aspect of physical and mental human health including intellectual ability [1-3]. Many commonly used pesticides have endocrine-disrupting and cancer-inducing effect [4]. Pathogenic microbes specifically infectious microorganisms are always a challenge to human survival. Increased healthcare awareness has led to the production of a wide range of antibiotics. However, the misuse of antibiotics for the last two decades has led to increase in the number of antibioticresistant pathogenic microorganisms. The resistant microorganisms cannot be cured using existing antibiotics and their contamination is a serious threat [5]. The agricultural land under cultivation is shrinking due to increasing urbanization. 
The first and second agricultural revolutions gave birth to agricultural and agricultural practices. Introduction of green revolution very well conceptualized the harnessing of resources for sustainable agricultural yield by making use of chemical fertilizers, herbicides, pesticides, and high-yield crop varieties [6]. However, the idea and use of chemical agents not only supported the agricultural yield on short time scale but introduced the chemical toxicity to air, water, and soil in a longer time frame [7]. This has, thus, led to the requirement of another agricultural revolution aimed at sustainable crop productivity with least environmental toxicity. Hence, focus is on exploring the scope of various nanomaterials as agricultural promoters. Later, advent of genetic engineering and production of resistant varieties was projected as better alternative to use of pesticides. But it has also added new class of biological contaminants in the form of genetically modified organisms (GMO). GMO are also a serious threat to biodiversity, wildlife, and human health. The genetic modification of plants is banned in most of the countries even for agricultural purpose. However, the GMO are commonly used for the industrial-scale production of nutraceuticals, enzymes, pharmaceuticals, dyes, and beverages. GMOs directly pose great threat to living organism in current times. Hence, safer techniques to produce and handle GMO are urgently required [8・, 9•]. Contamination of soil and water due to heavy metals is also one of the major concerns. Heavy metal contaminants are contributed by atmospheric, domestic, mining, agricultural, pharmaceutical, textile, electronics, and other industrial activities. Arsenic, cadmium, chromium, lead, and mercury are labeled as toxic heavy metals with serious ill effect on the various human organs even at low concentrations [10]. Efforts are constantly being made to develop reliable and simple sensors for the detection of environmental pollutants. The amount of pollutant present is sensitive to the site and medium in which it is present. The routine analytical methods used for pollutant detection vary from one to another country. Sensor detects an analyte with the help of recognition component and converts this signal to understandable signal using transducer or transduction component (Fig. 1). Biosensor uses biological component as recognition element $[11 \bullet, 12 \bullet \bullet]$. In case of nanobiosensor, the nanotechnology component is used to improve the transduction process in terms of selectivity, sensitivity, reproducibility, durability, and cost-effectiveness. Few cases report nanomaterial as recognition as well as transuding element $[13,14]$. DNA nanosensors are nanobiosensors with DNA mostly as recognition and nanomaterials as transducing component. Large number of DNA-based nanosensor has been designed for various human applications including the detection of environmental pollutants [15••].

In the last few years, DNA components like ssDNA, dsDNA, mismatch DNA, CA rich, C rich, T rich, Gquadruplex, and aptamer have been used for the detection of pollutant. The commonly used nanomaterials include metallic, metal oxides, quantum dots (QDs), platinum (Pt), copper $(\mathrm{Cu})$, magnetic, tungsten disulfide (WS2), mesoporous silica (MSN), graphdiyne, graphene, and graphene oxide [16-22]. Gold ( $\mathrm{Au}$ ) and silica NPs have been labeled as competitively safer nanomaterials for sensor application [11•]. AuNPs are commonly used while silica NPs are not explored much for DNA nanosensor formation. Hence, various studies indicate a scope towards the designing and development of specific and selective DNA nanobiosensors for more robust screening of air, water, food, and soil. This review focuses on the strategies, challenges, and opportunities in designing DNA nanosensor related to health, food, and daily use essential materials (Fig. 2). The challenges and gap in the knowledge of design and use of DNA nanosensor for the detection of pathogenic microorganisms, antibiotics, pesticides, GMO, toxic metals, heavy metals, and other toxic pollutants are discussed in detail.

The aim of this review is to update on recent advances in the field of DNA nanosensor and highlight the importance of DNA nanosensor for the detection of environmental pollutant. This review address application and scope of DNA nanosensor in pathogenic bacteria, GMO, antibiotic, pesticide, heavy metal, and other toxic pollutant detection. Pollutant interacts with DNA to exert a toxic effect. DNA-pollutant interaction is specific as particular pollutant leads to a particular toxic response. The ability of DNA to change specificity with change in its sequence and structure is useful for the sensing of diverse analytes. The combination of DNA with unique properties of nanomaterials has synergistic effect and wide scope. Interaction of DNA molecule with a type of analyte deciphers the type of response to be obtained. The use of ssDNA nucleotide, dsDNA, and aptamers with different levels of structural arrangement and complexity and its binding with complementary ssDNA strand having mismatch of single or more bases or no mismatch also creates a lot of possibilities. Hence, the tendency and response of DNA interaction with biological or chemical molecules has scope towards multifarious detection applications with lower limitations. Binding of ssDNA or dsDNA in DNA nanosensor with analyte induces change in color, UV-visible absorption intensity, and/or wavelength of nanomaterials. Only few nanomaterials have been tested for designing of optical DNA nanosensor. AuNPs and AgNPs are most commonly used nanomaterials for DNA nanosensor development. However, these are only used for few analyte detections, thus limiting their exploitation to full. QDs, iron oxide, magnesium oxide, and manganese oxide NPs have been used as optical nanosensor and can also be explored to design DNA nanosensor for large number of unexplored analytes as an alternative to routine complex analytical assays. Luminescence, chemiluminescence and phosphoresce abilities of nanomaterials are still neglected and not explored using existing nanomaterials and available DNA sequences $[23,24]$. Change in the properties of intercalating fluorescent 


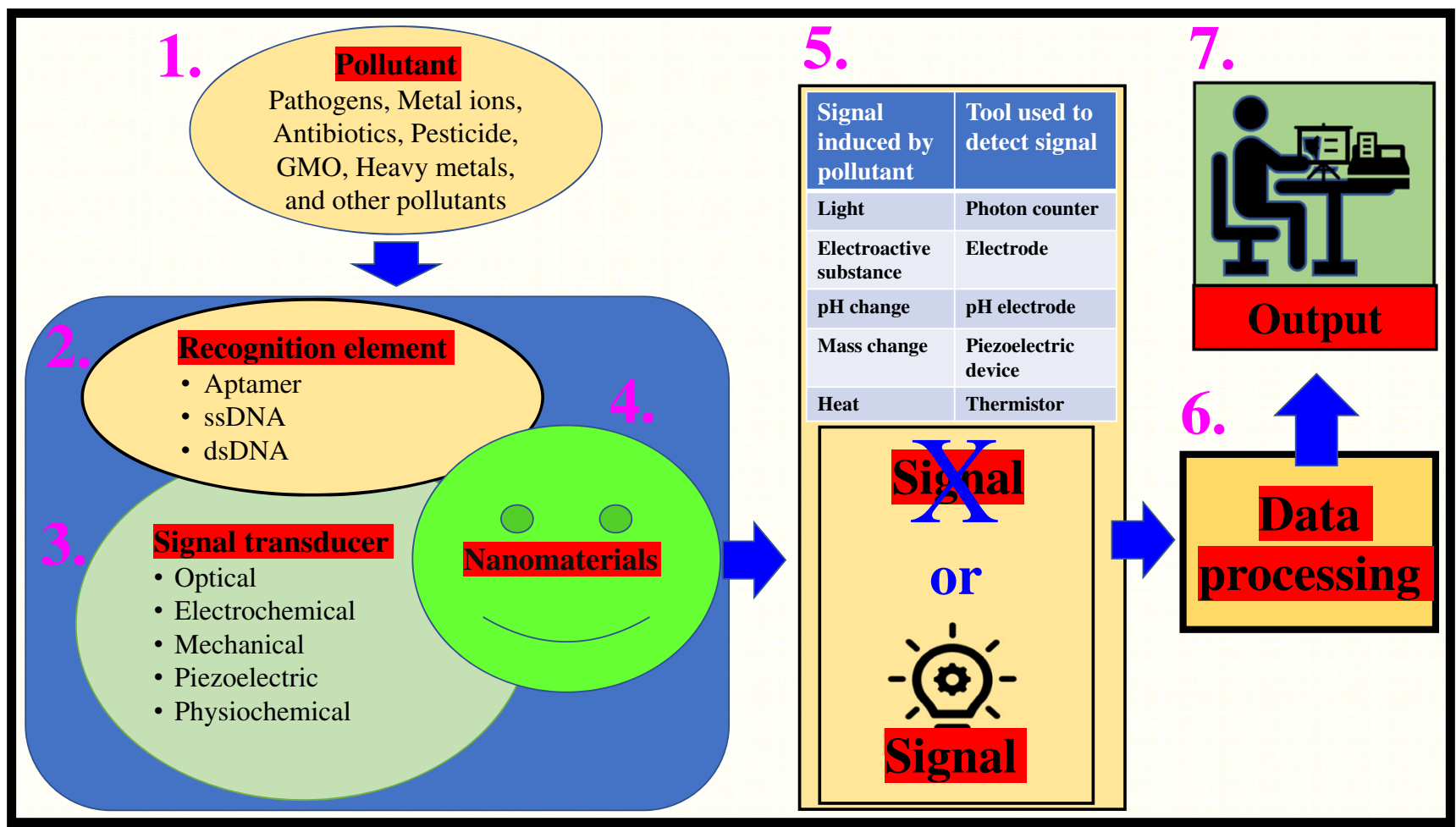

Fig. 1 The schematic representation of principle of environment pollutant detection. The pollutants interact with DNA nanosensor to produce signal or to suppress signal. The type of signal may vary from light, electroactivity, $\mathrm{pH}$ change, mass change, and heat change upon

dyes or electroactive substances in presence and absence of analyte leading to change in florescence or electrochemical signal also has great scope. In this case, the DNA needs to possess preferential binding for analyte rather than complementary sequence or other interfering molecules present in the test sample. Only few dyes and electroactive substances have been used for limited number of analytes. The similar strategy needs to be tested for more analytes as it has ease of detection and does not need complex time-consuming steps [25-27••]. Further, we need to have better predicting software that can predict the kind of sequence required for absolute specificity even in presence of closest interfering molecules. It has been reported in very few studies but missing in large number of studies. Bioinformatic tools and software need to be redesigned to have more accuracy in predicting DNA aptamer and their specificity towards multiple analytes in a complex medium. More nanomaterials need to be explored for electrochemical sensing applications. New nanomaterials can be designed that can detect even small change in electrochemical signals. Only few analytes have been tested using electrochemical approach. Better nanomaterials with better conductivity and easy control over conductivity need to be designed and integrated with their functionalization with variable underexplored DNA sequences. The functionalization of DNA with some unique tag molecules like antibodies, florescent molecule, and enzymes can be explored to improve the sensitivity of DNA nanosensor for interaction with pollutant in a concentration-dependent manner. The data is processed using a data processing system and output is produced in a readable format

pollutants that do not fluoresce and do not generate any electronic and/or other signals. More sequence variation in DNA, introducing more DNA mismatch between complementary DNA strand for better selectivity, better procedures for attachment of DNA to nanomaterials, functionalization of nanomaterials with various functional groups, and synthesis of noble nanomaterials are some of the opportunities to be addressed for improvement in existing DNA nanosensor. Apart from the above technical aspect, the safety concerns of nanomaterials are largely ignored. Almost all studies used nanomaterials prepared using one or other chemicals that contaminate environment itself. Alternative to use of chemicals is use of better approach, green nanotechnology. In the last decade, there are a lot of studies raising concern regarding safety concerns of nanomaterials as these materials can invade any cell and organelles to interact at biomolecule level [14, 28 $]$. The toxicity of nanomaterial to be used as component of DNA nanosensor needs to be thoroughly investigated before declaring it fit for use. It would help in exploring the huge potential of nanomaterials in the best possible way.

\section{Detection of Pathogens}

Pathogenic bacteria, fungi, and viruses can contaminate water, soil, and air. Water and food contamination are global 
problems. Detection of bacteria at lowest possible level is required to avoid any contagious disease outbreak, epidemic, or even pandemic-like situation. The traditional-, biosensor-, and nanosensor-based methods have their own advantages and disadvantages as shown in Table 1.

DNA-based nanosensor has been used to specifically detect pathogenic microorganisms like Vibrio cholera, Escherichia coli, methicillin-resistant Staphylococcus aureus (MRSA), Aspergillus, Candida, and Bacillus subtilis (Table $1)$.

Water-borne microbe $V$. cholera can be identified using selective binding of $O 1 \mathrm{OmpW}$ gene with two DNA probes. Magnetic NP-probe1-O1 OmpW-fluorescein amidite (FAM) probe2-AuNP complex formation occurs only if $V$. cholera is present in the test sample. The FAM probe can be isolated and quantified using fluorescence [29]. Fluorescent DNA-functionalized nanomaterials have many advantages in terms of DNA sequence-dependent fluorescence, easy functionalization, wide availability, water solubility, and excellent biocompatibility [34]. Binding of the heat-labile toxin LT1 gene of enterotoxin-producing E. coli with DNA probe-
AuNPs induces visible change in the color of NPs from red to purple [35]. Capture probe DNA-AuNPs preferably bind to aptamer and remain stable in the presence of G-quadruplex having complementary sequence to capture probe. In case of presence of common intestinal pathogen $E$. coli $K 88$ in the test sample, aptamer leaves capture probe-AuNPs and preferably forms complex with E. coli. The G-quadruplex binds to capture DNA-AuNPs to induce the aggregation and color change of AuNPs [26•]. AuNP-based DNA nanosensors are most commonly used for microorganism detection (Fig. 3).

ssDNA isolated from MRSA can induce sandwich complex formation between complementary ssDNA-AuNPs and ssDNA probe-fluorescent nanobeads. The complex formation leads to decrease in Brownian motion as compared to unbound nanobeads that can be analyzed using diffusometry $[27 \cdot \bullet]$. AuNP spots functionalized with ssDNA complementary to target microorganism DNA undergo change in local refractive index that can be detected through spectroscope. This sensor can detect several pathogenic fungi and bacteria simultaneously as shown in Table 1 [29]. Large number of microorganisms are still unexplored. The use of DNA

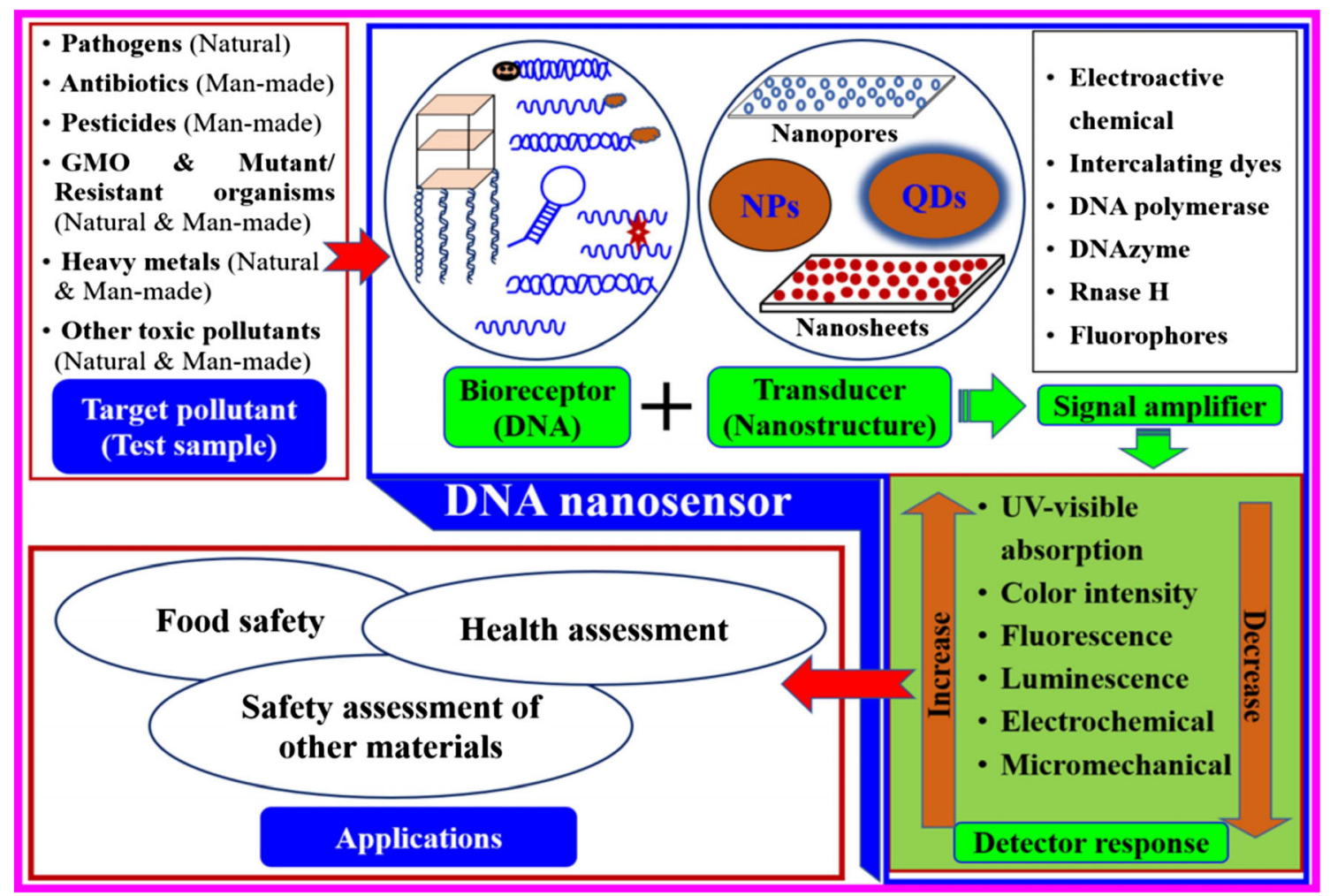

Fig. 2 Schematic DNA-based nanosensor for detection of environmental pollutants related to (i) human health like pathogens and antibiotics; (ii) food safety like pesticide and GMO; and (iii) other environmental pollutants like toxic metals, heavy metals, and other chemicals. The pollutants specifically interact with bioreceptor, DNA molecules of different sequence and structure to induce change in properties that is converted to appropriate signal by transducer. Nanomaterials can be used to improve the response of bioreceptors or transducer or both depending upon the exact nanosensor. The signal generated can be further amplified to enhance the sensitivity and specificity in a complex test sample and final amplified signal is recorded in the form of relevant change in optical, electronic, and mechanical properties. Constant efforts are being made and required in near future to make DNA nanosensors absolutely specific and ultrasensitive to desired test pollutant even in complex test medium containing large number of similar interfering molecule and its limit of detection should be low to detect minimum possible amount of pollutant 
Table 1 The advantages and disadvantages of traditional-, biosensor-, and nanomaterial-based methods for the detection of pathogen. Reproduced with permission from [29], MDPI

\begin{tabular}{|c|c|c|c|}
\hline Methods of pathogen and endotoxin detection & Advantages & Disadvantages & References \\
\hline \multicolumn{4}{|l|}{ Traditional methods } \\
\hline Immunology-based method & High selectivity and sensitivity & Real-time pathogen detection not possible & {$[29,30]$} \\
\hline Count method of culturing and colony & High demand & $\begin{array}{l}\text { Laborious; takes } 2-3 \text { days for initial } \\
\text { results; } 1 \text { week to determine the specific } \\
\text { pathogenic microorganisms }\end{array}$ & [29] \\
\hline Polymerase chain reaction method (PCR) & Popular; sensitive & $\begin{array}{l}\text { Complex to perform; require costly } \\
\text { instruments and trained personnel }\end{array}$ & [29] \\
\hline \multicolumn{4}{|l|}{ Biosensor and nanosensor } \\
\hline Optical biosensor & Successful; reliable and label-free detection & Costly & {$[29,31,32]$} \\
\hline Electrochemical biosensor & $\begin{array}{l}\text { Low cost; requires large quantity of sample; } \\
\text { automation and label-free detection } \\
\text { feasible }\end{array}$ & $\begin{array}{l}\text { Low specificity and sensitivity; needs a } \\
\text { lot of washing steps }\end{array}$ & {$[29,31,32]$} \\
\hline Mass-sensitivity-based biosensor & $\begin{array}{l}\text { Low cost; fast; easy operation, can detect } \\
\text { in real-time; detection is label-free }\end{array}$ & $\begin{array}{l}\text { Low specificity and sensitivity; requires } \\
\text { long incubation time and problematic } \\
\text { to regenerate the crystal surface }\end{array}$ & {$[29,31,32]$} \\
\hline Nanosensor & $\begin{array}{l}\text { Medium cost; excellent stability; low } \\
\text { detection limit; user friendly; measurement } \\
\text { can be done in real time }\end{array}$ & $\begin{array}{l}\text { Toxicity concerns of the nanomaterial } \\
\text { and difficulty in sensor regeneration }\end{array}$ & {$[29,33]$} \\
\hline
\end{tabular}

nanosensor for virus detection is less explored but has huge scope [37].

\section{Antibiotic Detection}

Contaminating antibiotics are contributed by industries producing antibiotics, human waste, and animal farming. The antibiotics used for animal farming are cheap and specifically hazardous to human and environment. DNA nanosensor can detect different antibiotics in water and complex biological medium (Table 1). Aptamer-AuNPs stayed stable in salt solution in absence of ofloxacin (OFL). Presence of OFL in water and synthetic urine samples induced aggregation of AuNPs that can be visualized with color change from red to purple/ blue [38]. AuNPs are aggregated by salt due to preferential binding of aptamer to FAM-labeled complementary strand in solution. There is strong emission of fluorescence by FAM and the color of solution appears blue. In presence of streptomycin, aptamer preferably binds to antibiotic. The FAM-labeled ds-DNA binds to AuNPs avoiding salt precipitation leading to florescence quenching by AuNPs and appearance of red color [39, 40]. Release of ochratoxin A (OTA) aptamer adsorbed on the exit gate of rhodamine B-loaded MSN pores in the presence of OTA in the test sample has been used for designing OTA florescence sensor. The nanosensor was used to detect OTA in commercially available foodstuffs [41]. Three-dimensional graphene-AuNP composite-coated glassy carbon electrode was functionalized with oxytetracycline (OTC) antibodies. OTC present in the test sample binds to
Fig. 3 Schematic for gold NPoligonucleotide conjugate-based detection of microorganism. Reproduced with permission from Jamdagni et al., Springer Nature [36]

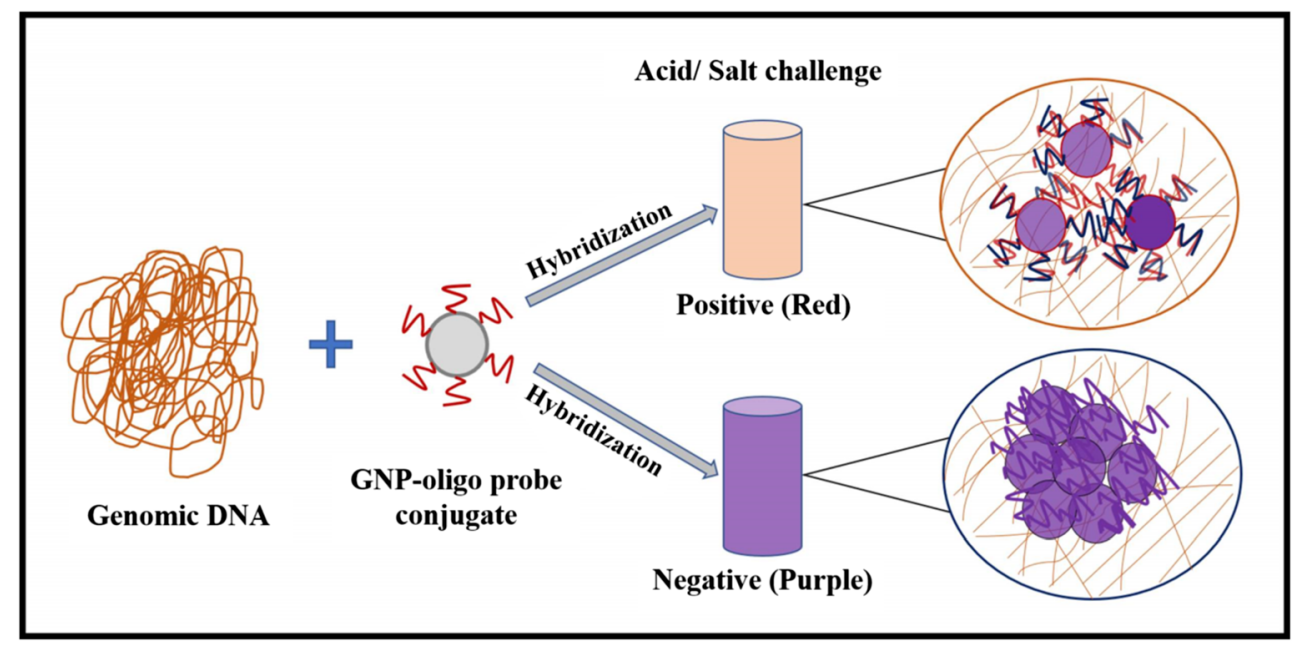


the antibodies and is detected using aptamer-AuNPs containing horseradish peroxidase. The horseradish peroxidase promoted catalysis of hydrogen peroxide to produce peak current [42]. The surface of thionine-decorated graphene was functionalized with aptamer containing hierarchical nanoporous platinum-copper alloy to develop a differential pulse voltammetry (DPV)-based kanamycin biosensor. Thionine-coated electronically conductive graphene provides support to aptamer hierarchical nanoporous platinum-copper that ultimately promotes the electroactivity. Binding of kanamycin present in pork meat and chicken liver with aptamer induces decrease in DPV current [16]. Carbendazim present in the lettuce and orange juice sample binds to the surface of AuNPs and impedes the electron transfer to carbon nanohorns/aptamer-AuNP nanocomposite-coated electrode [43••]. Ampicillin present in the human serum, river water, and milk samples binds to aptamer-nanosheet-modified gold electrode that leads to charge transfer resistance. Aptamer Gquadruplex formation is responsible for increase in charge transfer resistance value [44]. Among various types of aptasensors, more than 50\% sensors are electrochemical in nature. Electrochemical DNA aptamer-based nanosensors offer cost-effective and faster multiplexed analysis with better sensitivity and specificity as compared to other biosensors [45•].

A strip for direct detection of kanamycin in milk samples has been designed using DNA probes and AuNPs. AptamerAuNP binds with another silver-bound complementary DNA probe to form complex. The complex is captured at the test zone that contains a capture probe complementary to the $3^{\prime}$ end of DNA bound to AgNPs. Presence of kanamycin in test sample leads to release of AuNPs from complex and test region appears faded. The assay does not need several incubations and washing steps [46]. In a similar study using aptamerAuNPs, the magnetic microspheres were used to detect kanamycin in the form of faded band at test region on a nitrocellulose strip [47]. Non-enzymatic hybridization chain reactionbased nanosensor has been used for the detection of kanamycin in milk. Hairpin DNA probe attached to AuNPs prevents aggregation of AuNPs by salt in solution. Presence of kanamycin in test sample removes hairpin DNA from AuNPs surface and induces DNA straightening. It creates binding sites for another two complementary probes designed in such a way that cascade of mechanism of complementary strand binding and extension is triggered. The AuNPs get aggregated and detected in the form of color change to blue and reduction in UV-visible absorption intensity [48]. Similarly, gold bar is modified with Y-shaped DNA formed as a result of binding of aptamer and its complementary DNA. Presence of kanamycin triggers formation of hairpin-like structure. Hairpin structure has affinity for complementary sequence present over the magnetic NPs, thus releasing kanamycin and forming elongated dsDNA by incorporating the SYBR green I dye.
Increase in fluorescence intensity acts as an indicator for presence of kanamycin in milk, pork, and fish samples [49•]. Functional DNA-functionalized magnetic beads (MBs) have been used for the detection of tetracycline in honey samples [50]. Only limited numbers of NPs have been used for DNA nanosensor synthesis. More types of nanomaterials can be used to improve the detection efficiency of nanosensor (Fig. $4)$.

\section{Pesticide Detection}

Pesticides are toxic to human beings. High food safety standards warrant sensitive methods for pesticide detection. Pesticide categorization is complex as it contains around 100 classes with total number over 800 . The main classes that are being detected using DNA-based nanosensor are organophosphorus, carbamates, neonicotinoids, and triazines. There are various traditional- and sensor-based methods available to detect pesticides (Table 2).

Detection of other pesticides using nanosensor is discussed in detail elsewhere [22, 69]. Sensor designing focuses on high sensitivity, low limit of detection, and good selectivity along with cost-effectiveness. Currently, HPLC, GC-MS, and other analytical techniques are being used for pollutant detection. DNA nanosensors have been used for the detection of large number of pesticides (Table 1). Colorimetric DNA nanosensor has been designed for acetamiprid detection in celery and green tea leaves. The aptamer binding to ssDNAAuNPs undergoes salt-induced aggregation and the solution appears purple. Availability of acetamiprid leads to solubilization of ssDNA-AuNPs as a result of formation of red color aptamer-acetamiprid complex [70]. In a more complex approach, the mixing of fluorescent $\mathrm{CdTe}$ quantum dots $(\mathrm{CdTe}$ QDs) with aptamer-AuNPs leads to fluorescence quenching via an effect known as inner filter effect (IFE). In the presence of acetamiprid, the aptamer preferably binds to acetamiprid leaving AuNPs prone to aggregation by salt in solution and thus reviving the fluorescence of QDs. Acetamiprid detection was validated on vegetable samples [71]. The conductivity of glassy carbon electrode modified with aptamer-graphene$\mathrm{AgNP}$ nanocomposites is impeded by binding of acetamiprid in test sample with aptamer [72]. Aptamer-AuNPsmultiwalled carbon nanotube (MWCNT)-reduced GO nanoribbon nanocomposite-modified electrode has similarly been used for developing electrochemical acetamiprid impedimetric DNA nanosensor [73••]. $\mathrm{C}_{60}$-AuNPs act as energy donor while carbon dot acts as receptor to create electrogenerated chemiluminescence energy transfer (ECRET) for the detection of carbofuran. The presence of carbofuran in test sample induces structural change in aptamer to block the chemiluminescence [23]. Phorate, an organophosphate pesticide, can selectively induce aggregation of 


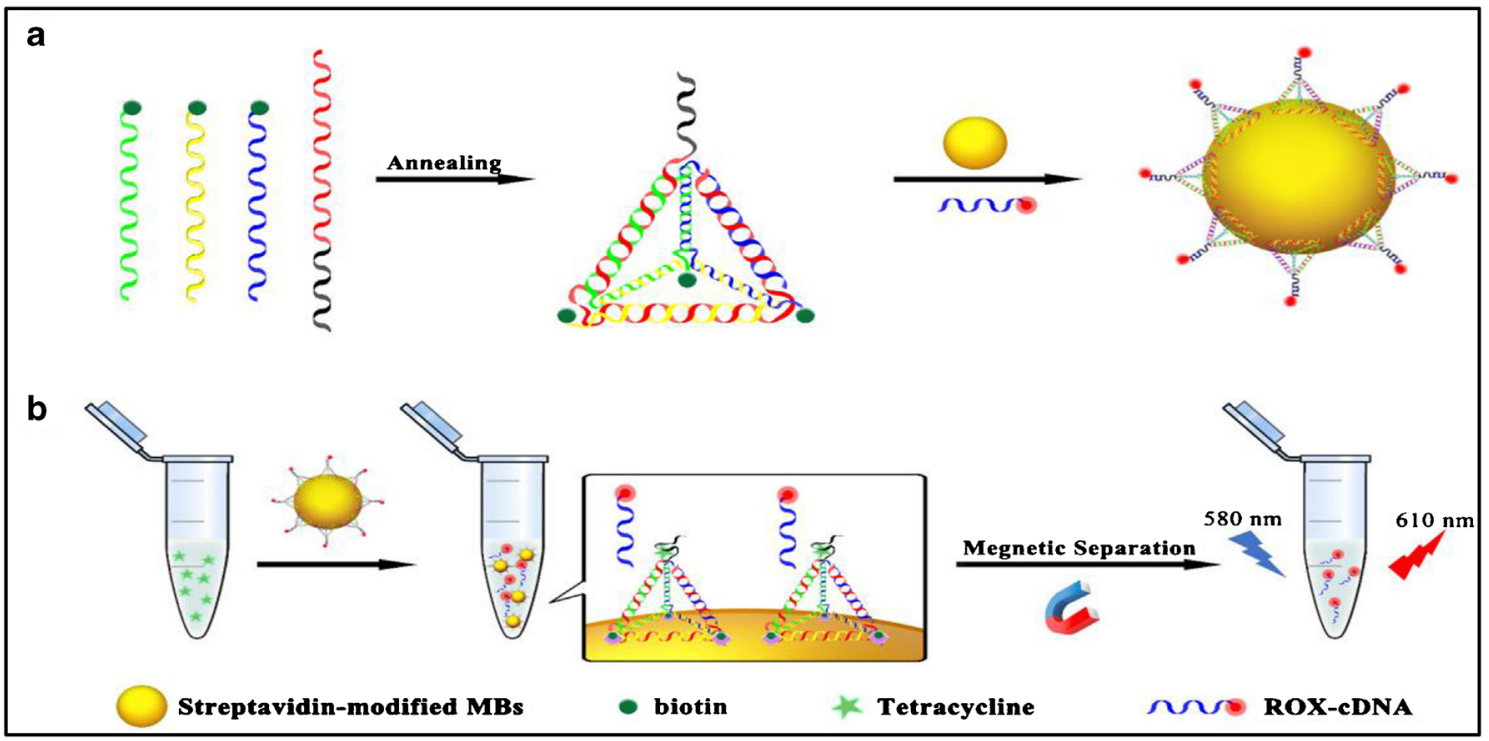

Fig. 4 a, b Experiment design for tetracycline detection using DNA tetrahedron nanostructure-functionalized MBs. Reproduced with permission from Hong et al., Elsevier 2020 [50]

ssDNA aptamer-AgNPs. Aggregation leads UV-visible absorption intensity reduction and change in NP solution color from brown to colorless [74], while acetamiprid can induce aggregation of ssDNA aptamer-AgNPs in the presence of $\mathrm{NaCl}$ salt to observe reduction in the UV-visible absorption peak intensity and color change from yellow to gray [75••]. Test sample is exposed to biotin-functionalized aptamer to form biotinylated profenofos-aptamer complex. The complex can bind onto the surface of capture DNA probe-AuNP/ polyaniline (PANI)-graphite-modified screen-printed electrode. The electrode is exposed to streptavidin-alkaline phosphatase enzyme conjugate in solution containing 1-naphthylphosphate. Phosphatase hydrolyzes 1-naphthyl-phosphate to 1-naphthol that can be electrochemically detected using differential pulse voltammetry (DPV) [76]. In contrast, methyl parathion and chlorpyrifos binding to specific ssDNA over electrode surface modified with acetylcholinesterase (AChE)
enzyme-SWCNT-ssDNA-AuNPs were found to inhibit AChE enzyme activity. Inhibition of enzyme activity led to $\mathrm{pH}$ change in a concentration-dependent manner as measured by electrode [77]. Parylene-C lipid layer film containing nanopores can be used to detect omethoate in vapor phase. Nanopores allow DNA-aptamer passage but block omethoateaptamer complex leading to decrease in membrane conductance that is measured using a patch-clamp amplifier [78].

A bio-barcode amplification-based competitive immunoassay has been developed for triazophos detection in water, apple, turnip, rice, and cabbage samples with sensitivity almost near to ELISA approach. AuNPs containing mAb as recognition elements and thiolated ss-oligonucleotide as barcodes were exposed to test sample containing pesticide and magnetic microparticle (MMP) probe functionalized with ovalbumin-pesticide-hapten (hapten-OVA). Triazophos in sample outcompetes ovalbumin-pesticide-hapten and binds

Table 2 Different methods of pesticide detection in soil, water, vegetables, and crops

\begin{tabular}{|c|c|c|c|c|c|}
\hline Approach & Technique & Sample type & Advantage & Disadvantage & Reference \\
\hline Traditional & $\begin{array}{l}\text { High-performance liquid } \\
\text { chromatography } \\
\text { Gas chromatography } \\
\text { Liquid chromatography }\end{array}$ & $\begin{array}{l}\text { Water, fruit, vegetable } \\
\text { Water, fruit, vegetable, soil } \\
\text { Water, fruit, vegetable, soil }\end{array}$ & $\begin{array}{l}\text { High selectivity and sensitivity; } \\
\text { high demand, popularity }\end{array}$ & $\begin{array}{l}\text { Complex method to perform; } \\
\text { require costly instruments } \\
\text { and trained personnel }\end{array}$ & [51-54] \\
\hline Nanosensor & $\begin{array}{l}\text { Electrochemical } \\
\text { Optical } \\
\text { Colorimetric } \\
\text { Piezoelectric mass sensitive } \\
\text { Chemiluminescence } \\
\text { Fluorescence }\end{array}$ & $\begin{array}{l}\text { Water, fruit, vegetable, soil } \\
\text { Water, fruit, vegetable } \\
\text { Water, fruit, vegetable } \\
\text { Water, fruit, vegetable } \\
\text { Water, vegetable } \\
\text { Water, fruit, vegetable }\end{array}$ & $\begin{array}{l}\text { Excellent stability; low detection } \\
\text { limit; user friendly; } \\
\text { measurement can be done } \\
\text { in real time }\end{array}$ & $\begin{array}{l}\text { Toxicity concerns of } \\
\text { nanomaterial; } \\
\text { sensor regenerate difficult }\end{array}$ & $\begin{array}{l}{[55-57]} \\
{[58-60]} \\
{[61,62]} \\
{[63,64]} \\
{[23,65]} \\
{[66-68]}\end{array}$ \\
\hline
\end{tabular}


to AuNPs. Washing under magnetic field removes unbound AuNPs. Detection is done by AuNPs catalyzed Ag staining. The gray color intensity of Ag depends upon the concentration of triazophos in test sample [79]. Fluorogenic RNA bound to a quencher forms complex with mAb-AuNP-DNA probe fixed on plate. Ribonuclease $H$ (RNase $H$ ) can specifically cut RNA in the DNA-RNA hybrid to generate fluorescence signal. In presence of triazophos, there is fluorescence quenching as the mAb-AuNP-DNA probe binds to triazophos and DNA-RNA hybrid is not formed. The bio-barcode immunoassay-based nanosensors were used to detect the triazophos residue in agricultural products and water samples (Fig. 5) $[80 \bullet \bullet$.

\section{Detection of GMO, Mutated, and Resistant Organisms}

GMO possess modified DNA that contains transgene and some other sequences like promoter and selection markers. Likewise, mutated and resistant organism contains DNA sequences different from normal organisms. The sequences complementary to these specific sequences are used as bioreceptor to provide specificity to DNA nanosensor as summarized in Table 3.

\section{Microorganism}

Penicillin-binding protein-encoding gene is responsible for the antibiotic resistance of microbes like MRSA. Presence of $P B P 2 a$ DNA in test sample induces change in peroxidase activity of $\mathrm{GO} / \mathrm{Au}$ due to release of $P B P 2 a$-specific aptamer from AuNP-GO surface. This ultimately leads to variation in the UV-visible absorption intensity [81]. The recovery of fluorescence intensity is used to quantify rifampicin-resistant Mycobacterium tuberculosis. FAM-labeled probe specific for mutated DNA sequence providing rifampicin resistance to $M$. tuberculosis is adsorbed on the surface of graphdiyne nanosheets. The nanosheet quenches the fluorescence of FAM probe. In the presence of target ssDNA, the FAM probe is released from nanosheet to form complex with target DNA (Fig. 6) [20]. IS6110 fragment of M. tuberculosis present in the resistant test sample specifically binds to signal probeAuNP-fullerene/graphene nanosheet that act as signal tag to generate electrochemical signal [82]. M204I mutation leads to lamivudine or telbivudine antiviral therapy resistance in hepatitis B virus (HBV). In the presence of resistant HBV in test sample, one end of mutated DNA is bound to glass slide functionalized with probe while second end binds to biotinlabeled ssDNA that further binds with streptavidin-labeled QDs. QDs can be detected using fluorescence microscopy [19]. ssDNA of MRSA binds to form sandwich complex with ssDNA-MNPs on one side and ssDNA-AuNP-ferrocene probe on other side. The complex is isolated using magnetic field and subjected to electrochemical analysis on screenprinted electrode. AuNP-ferrocene produces chronoamperometric response. Dye-linked L-proline dehydrogenase (L-proDH) can also be added to solution to increase the oxidation of ferrocene leading to more prominent electrochemical signal [90].

MRSA containing mecA target ssDNA interacts with carboxy fluorescein (FAM)-ssDNA-GO and removes FAM ssDNA to form double-stranded mecA-ssDNA FAM-SYBR Green I-ssDNA complex in the presence of intercalating

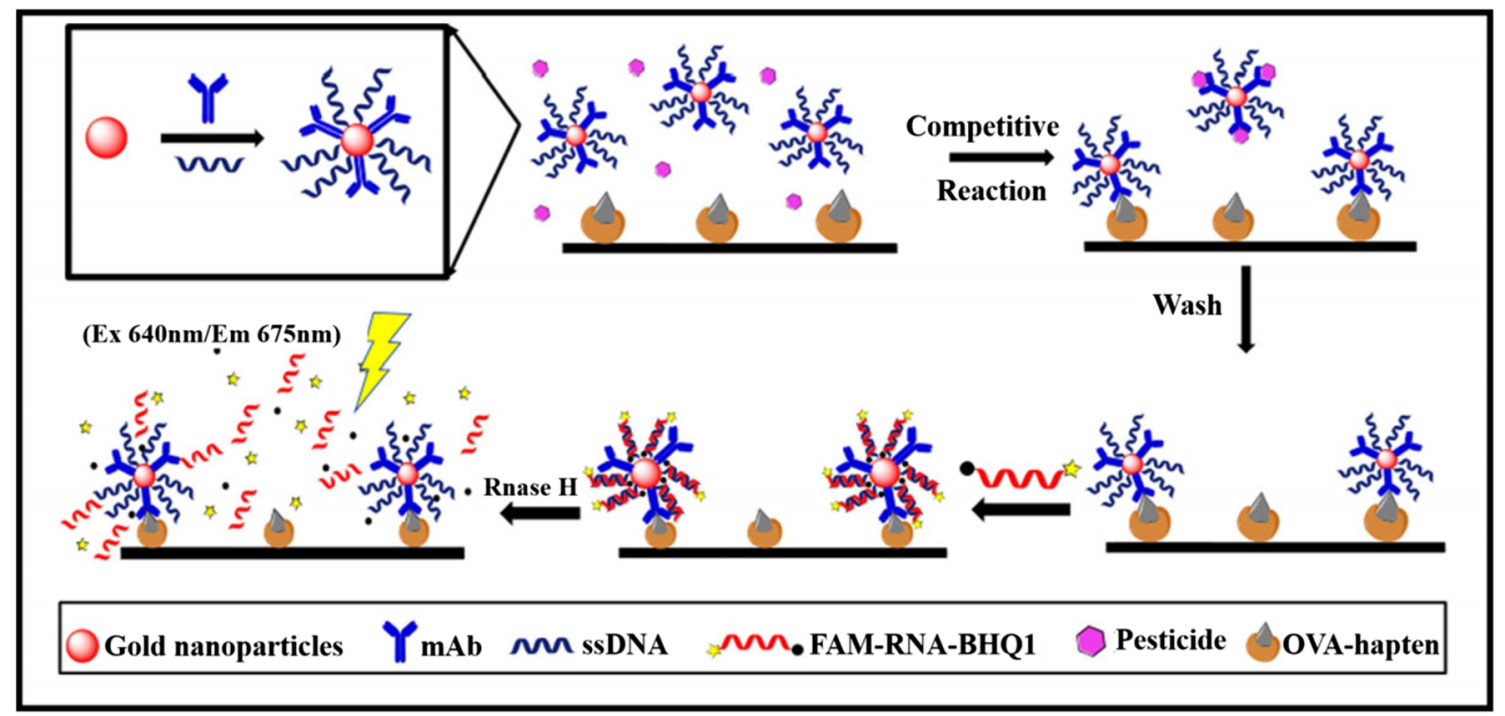

Fig. 5 Schematic representation of fluorometric bio-barcode immunoassay-based detection of triazophos by iterative cycles of DNA-RNA hybridization and dissociation of fluorophores by Ribonuclease H. ssDNA- and mAbs-labeled AuNP acts as a signal generator. The fluorescence signals were generated through DNA-RNA hybridization and subsequent specific hydrolysis of Ribonuclease $\mathrm{H}$. Reproduced with permission from Zhang et al., Elsevier [80••] 


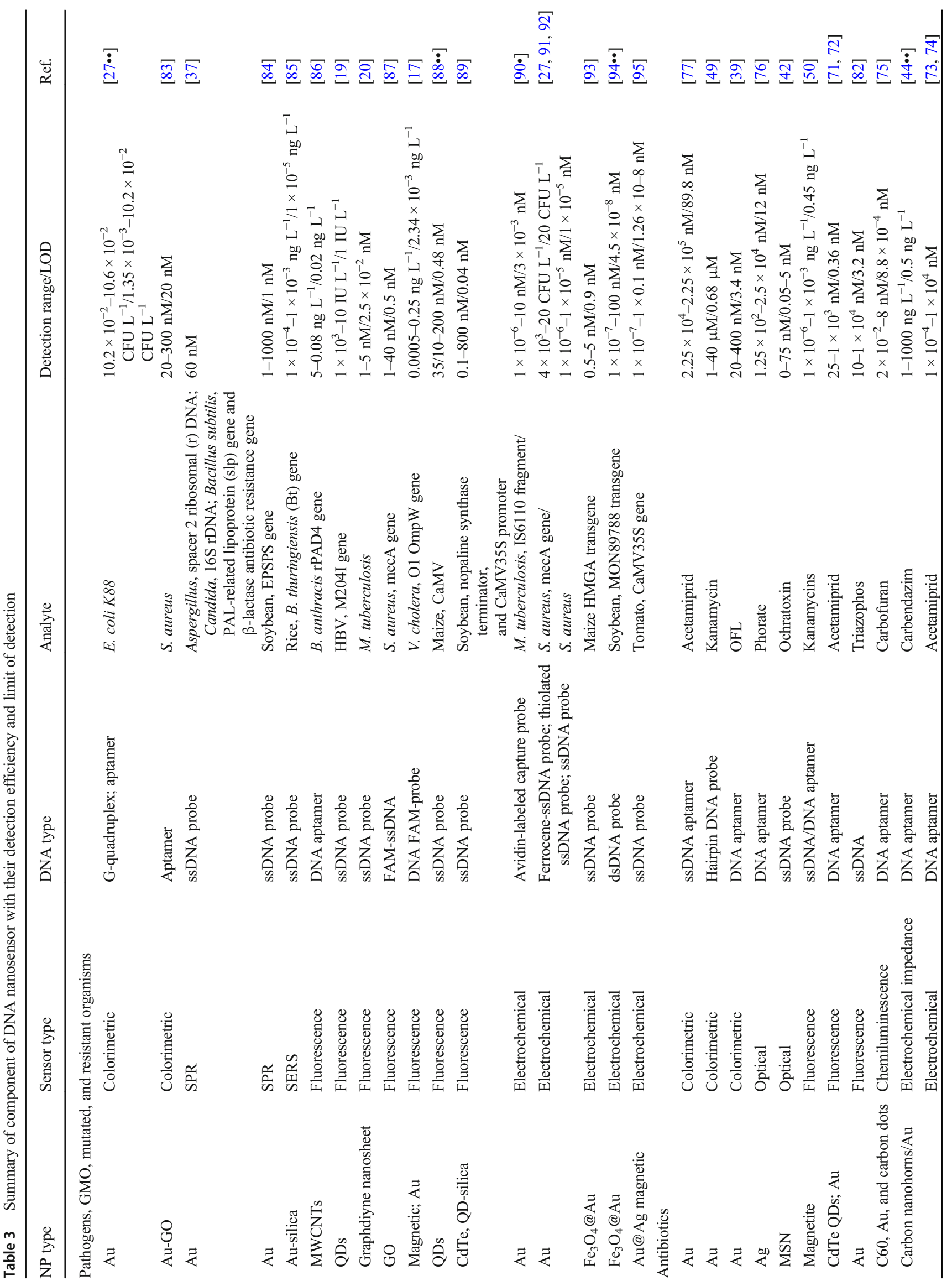




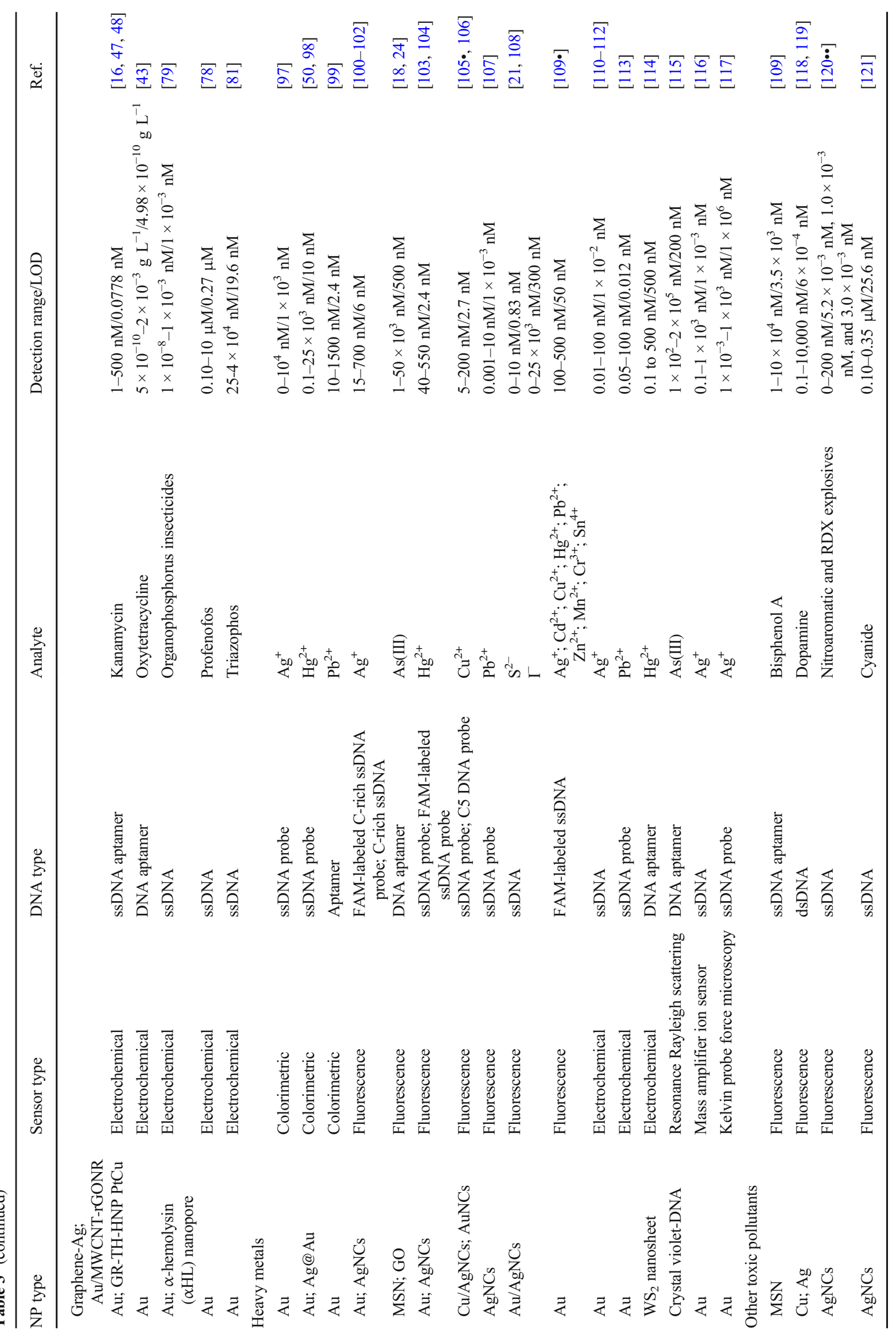




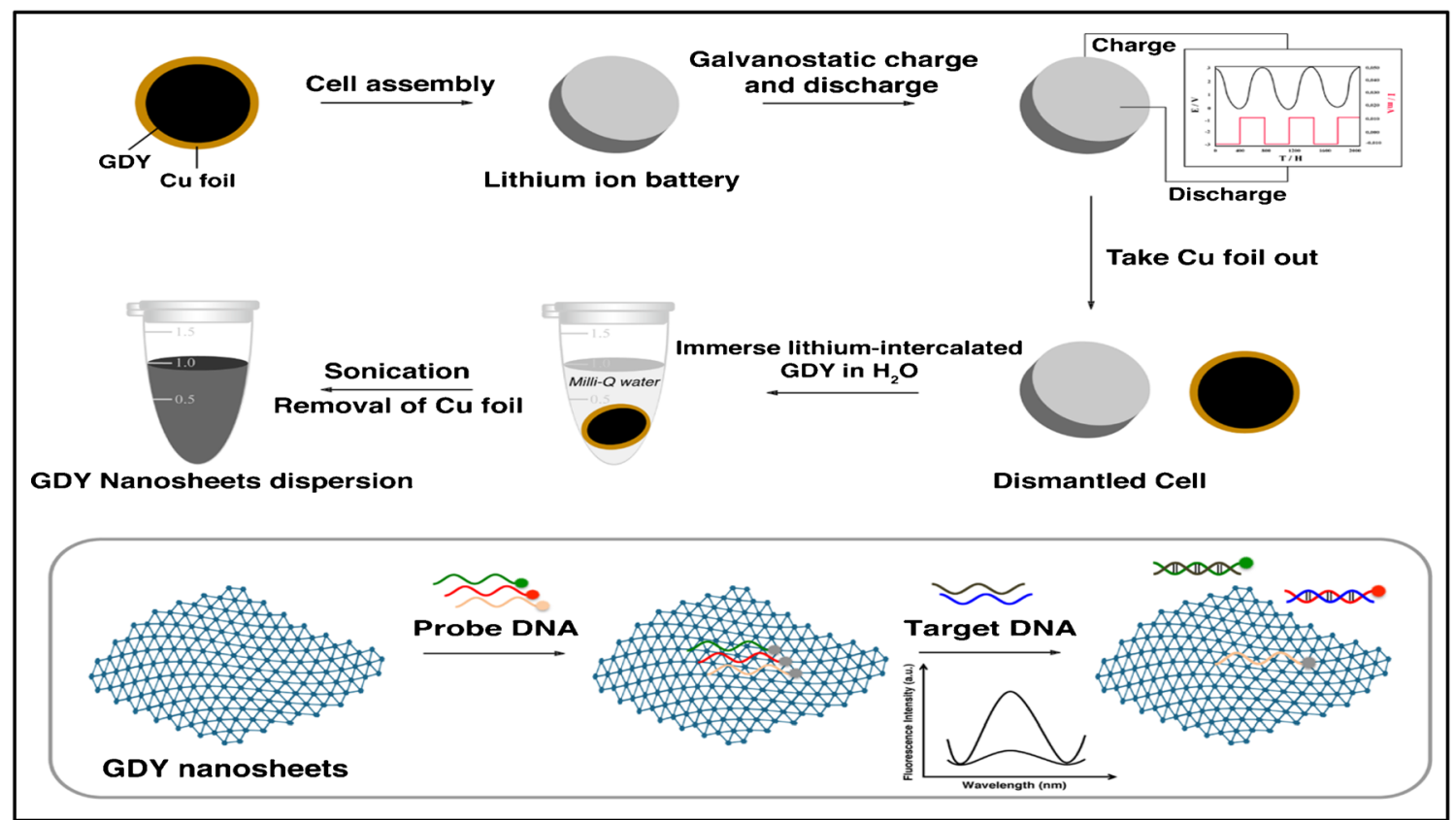

Fig. 6 Scheme showing detection of drug-resistant Mycobacterium tuberculosis using graphdiyne nanosheet-based fluorescent assay. The graphdiyne (GDY) nanosheets are prepared by electrochemical lithiumintercalation process. The nanosheets bind to ssDNA and efficiently quench the fluorescent group attached to the end of ssDNA. Presence

fluorescent dye SYBR green I. SYBR green is further incorporated as the polymerase present in the solution extends target DNA using FAM ssDNA as template leading to increase in the fluorescence intensity [92]. Certain MRSA contains plasmin-sensitive cell wall proteins. Plasmin-sensitive protein interacts with IgG-MNPs and anti-PI-antibody-AuNP-oligonucleotides to form sandwich complex. Magnetic field is used to isolate complex and the oligonucleotides are quantified in the form of magnitude of reduction peak current using square wave voltammetry [87]. Interaction of domain 4 protective antigen of Bacillus anthracis with gel green-labeled aptamer-MWCNTs induces decrease in fluorescence intensity [93]. DNA sequence that codes for protein responsible for pathogenesis or drug resistance can be explored to develop nanosensor for unexplored mutant, drug-resistant, and genetically modified pathogens.

\section{Plants}

Change in localized surface plasmon resonance signal of DNA probe-AuNP-modified cuvette attached to sensor chip upon binding of target 5-enolpyruvylshikimate 3-phosphate synthase genes has been used for designing portable sensor. Enolpyruvylshikimate 3-phosphate synthase transgene provides herbicide resistance to soybean [86]. Fluorescent CdTe QD-silica nanospheres functionalized with probe specific for nopaline synthase terminator and cauliflower mosaic virus $35 \mathrm{~s}$ (P35S) promoter sequence of transgenic soybean bind with of target ssDNA form a duplex with ssDNA, thus releasing the dsDNA from the nanosheets. The fluorescence recovers depending upon the presence of target ssDNA of the $M$. tuberculosis. Reproduced with permission from Chang et al., American Chemical Society, 2019 [20]

target ssDNA to induce decrease in fluorescence intensities [84]. Genetically modified CaMV 35S marker sequence of Maize (Zea mays L.) binds to specific probes-QDs that leads to increase in the grain size of QDs because of aggregation and self-assembly. Aggregation ultimately leads to reduction in the phosphoresce intensity of QDs [90•]. Binding of Bt gene of transgenic rice sample with probe-AuNP-silica nanocomposite induces change in surface-enhanced Raman scattering signal [88••]. Loop containing dsDNA- $-\mathrm{Fe}_{3} \mathrm{O}_{4} @ \mathrm{Au}-\mathrm{MNPs}$ interacts with target soybean DNA to form open-loop structure and activates exonuclease III releasing the target transgenic DNA and converting the loop dsDNA to ssDNA. ssDNA can interact with ssDNA-AuNP-Phi29 DNA polymerase-T4 DNA ligase complex to initiate a rolling circle reaction-based synthesis of DNA. DNA acts as support for $\left[\mathrm{Ru}\left(\mathrm{NH}_{3}\right)_{6}\right]^{3+}$ attachment leading to increase in chronocoulometric signal [85]. Fluorescein isothiocyanate containing ssDNA signaling probe binds with maize taxon-specific transgenic ssDNA that ultimately binds to amino-modified ssDNA probe specific for maize taxon-specific transgene that is attached to superparamagnetic core shell $\mathrm{Fe}_{3} \mathrm{O}_{4} @ \mathrm{AuNP}$-coated gold electrode. Anti-fluorescein peroxidase is attached to generate a chronoamperometric response [95]. While detecting transgenic tomato, one end of target CaMV35S ssDNA of transgenic tomato binds with the ssDNA-MWCNTs present on the surface of glassy carbon. Other end of target DNA binds with ssDNA- $\mathrm{Fe}_{3} \mathrm{O}_{4}-\mathrm{Au} @ \mathrm{Ag}$ nanocomposite to form sandwich structure. The $\mathrm{Fe}_{3} \mathrm{O}_{4}-\mathrm{Au} @ \mathrm{Ag}$ nanocomposite catalyzes 
hydrogen peroxide $\left(\mathrm{H}_{2} \mathrm{O}_{2}\right)$ reduction to produce increase in current $[94 \bullet \bullet]$. The DNA sequence used for screening of genetically modified plants can also be efficiently used for designing a DNA nanosensor for large number of GMO expected to be produced in the near future.

\section{Metal and Heavy Metal Detection}

Arsenic, mercury, lead, cadmium, and chromium are the most commonly found heavy metal contaminants. These toxic metals can induce multiple organ damage and disturb human metabolomics. Exposure to high dose of these heavy metals may lead to morbidity and even mortality $[96,122]$. The dose, route of exposure, age, gender, genetics, and nutritional status of exposed organism affect the toxicity of metal ions. More than 250 vegetables in Chinese villages near industries accumulated heavy metals, lead, cadmium, chromium, mercury, and arsenic causing health hazards. Among various types of heavy metals, metal ions like chromium and $\mathrm{Pb}$ cause noncancer risks while $\mathrm{Cd}$ causes various types of cancer. Likewise, in India, chromium and cobalt accumulation into the food crops can induce cancerous and non-cancerous diseases [123]. Heavy metal enrichment in water and sediments as well as in various organs of fish and oyster has been reported from China, Persian Gulf, Turkey, and various other parts of the globe [124-126]. The specific binding of heavy metal ions to bioreceptor DNA molecule induces change in the properties of nanomaterials or DNA leading to qualitative and quantitative change in the signal. The change in signal generated may be fluorescence intensity, luminescence intensity, visible change in color, UV-visible absorption intensity, and shift in absorption wavelength, as well as change in microcantilever and electrochemical parameters like redox/anode/cathode current, impedance, and voltage. Fluorescence quenching approach has been used for the detection of sulfide ions $\left(\mathrm{S}^{2-}\right)$ in the hot spring and seawater samples. $\mathrm{S}^{2-}$ present in the test sample induces conformational change in the DNA probe present over the $\mathrm{Au} / \mathrm{Ag}$ nanoclusters that leads to fluorescence quenching. The sensor although requires addition of sodium peroxydisulfate to avoid non-specific interaction with interfering iodide ions $\left(\Gamma^{-}\right)$[127]. $\Gamma^{-}$-specific DNA template functionalized $\mathrm{Au} / \mathrm{Ag}$ nanoclusters undergo fluorescence quenching and color change from colorless transparent to purple red in the presence of $\Gamma^{-}$in test sample [21].

Presence of arsenic $[\mathrm{As}(\mathrm{III})]$ in the test sample removes aptamer guarding the pores of rhodamine B-loaded MSN leading to increase in the fluorescence intensity [18]. Recovery of fluorescence quenching due to As(III)-specific release of aptamer-nanorods bound to GO surface has been used to design luminescence resonance energy transfer (LRET)-based nanosensor [24]. As(III) is a carcinogenic pollutant. Aptamer-controlled synthesis of crystal violet has been used for sensing of As(III). Presence of As(III) in the test sample leads to increase in the size of small crystal violet nanomaterials prepared using DNA aptamer. The resonance Rayleigh scattering (RRS) intensity increases directly with increase in size of nanomaterial that depends upon the As(III) concentration [108]. Cytosine-rich DNA have affinity for $\mathrm{Ag}^{+}$. This affinity has been used to design DNA-based lateral flow test for the visual detection of $\mathrm{Ag}^{+}$in the tap and river water samples. In presence of $\mathrm{Ag}^{+}$, the C-rich oligonucleotide probe-AuNPs get immobilized in the form of red band on the test zone by forming $\mathrm{C}-\mathrm{Ag}^{+}-\mathrm{C}$ complex with second mismatched $\mathrm{C}$-rich oligonucleotide probe [115]. Crich ssDNA probe-AuNPs can bind to mismatched FAM fluorophore-labeled C-rich ssDNA probe in the presence of $\mathrm{Ag}^{+}$ions leading to increase in the fluorescence polarization signal [97]. Presence of C-rich ssDNA-stabilized AuNPs induces FAM quenching in the solution. However, addition of sample containing $\mathrm{Ag}^{+}$induces conformational change in the DNA leading to AuNPs aggregation that leads to recovery of FAM florescence [100]. $\mathrm{Ag}^{+}$-induced dimerization and change in florescence has been used to detect $\mathrm{Ag}^{+}$. Two 12 cytosine-containing mismatched DNA attached to AgNCs (Cyt12-AgNCs) undergo dimer formation in the presence of $\mathrm{Ag}^{+}$ions. The fluorescence of Cyt12-AgNCs changes from red to green on dimerization [101•]. CA probe-based electrochemical nanosensor has been designed for $\mathrm{Ag}^{+}$detection in antimicrobial drug, sulfadiazine. Gold electrode was modified with CA probe such that adjacent probes undergo duplex formation in the presence of $\mathrm{Ag}(\mathrm{I})$ through $\mathrm{C}$-silver ion-C and $\mathrm{C}$ $\mathrm{Ag}^{+}-\mathrm{A}$ complex formation. Complex formation leads to reduction in electrochemical peak current $[102,110]$. To design an electrochemical sensor, AuNPs-modified carbon paste electrode modified with poly-C ssDNA is exposed to complementary mismatched poly-C ssDNA. Two strands can only bind in presence of $\mathrm{Ag}^{+}$to induce decrease in the reduction peak current [111]. Attachment of ions to microcantilever can induce change in resonance frequency. ssDNA is attached to microcantilever and its complementary mismatched ssDNA attached to AuNPs is added in solution. Mismatched strand can bind to cantilever in the presence of $\mathrm{Ag}^{+}$only [112••]. Kelvin probe force microscopy-based DNA nanosensor has been designed for $\mathrm{Ag}^{+}$detection in drinking water. A conductive cantilever is exposed to AuNPs functionalized with approximately 100 ssDNA probes. Complementary target ssDNA having 4 nucleotide-mismatched bases can bind with AuNPs probe only in presence of $\mathrm{Ag}^{+}$. Binding of target DNA induces change in surface potential that depends upon the concentration of $\mathrm{Ag}^{+}$[116].

Fluorescence quenching of C-rich DNA-functionalized AgNCs and $\mathrm{Cu} / \mathrm{AgNCs}$ in the presence of $\mathrm{Hg}^{2+}$ and $\mathrm{Cu}^{2+}$ has also been explored for designing simple DNA nanosensor $[117,128,129]$. AuNPs functionalized with thymine (T)-rich DNA template containing FAM at distant end undergo 
fluorescence quenching in the presence of $\mathrm{Hg}^{2+}$ to induce folding of DNA template bringing FAM in close proximity with AuNPs [103]. The agglomeration of $\mathrm{Au}$ and $\mathrm{Ag} @ \mathrm{Au}$ nanoplates in the presence of $\mathrm{Hg}^{2+}$ leads to change in color from red to purple. The $\mathrm{Ag}^{+}$interferes with $\mathrm{Hg}^{2+}$ detection that can be avoided by functionalization of the nanoplates with poly-deoxycytidine sequence [104]. Circular template and DNA polymerase can lead to circular elongation of AuNPbound T-rich oligonucleotide over a circular template in a rolling circular mechanism. In case of test sample containing $\mathrm{Hg}^{2+}$, the preferential binding of T-rich oligonucleotide to $\mathrm{Hg}^{2+}$ prevents DNA elongation. Placing reaction mixture on a nitrocellulose-based paper leads to diffusion of DNA-bound AuNPs depending upon the size of DNA. Sample lacking $\mathrm{Hg}^{2+}$ travels large distance as small DNA sequence is attached to AuNPs. Increase in the concentration of $\mathrm{Hg}^{2+}$ in the test sample leads to low rate of diffusion of AuNPs due to attachment of larger DNA and it appears as dark spot in the center [130]. Release of aptamer bound to the surface of $\mathrm{WS}_{2}$ nanosheet-gold electrode in the presence of $\mathrm{Hg}^{2+}$ leads to decrease in peak current in concentration-dependent manner [98]. 3Mercaptopropionic acid (MPA)-induced fluorescence quenching of DNA-Cu/Ag nanoclusters due to MPA and the $\mathrm{Cu} / \mathrm{Ag}$ cluster interaction induced alteration in conformation of DNA. Presence of $\mathrm{Cu}^{2+}$ in soil and pond water samples inactivates MPA leading to recovery of fluorescence [114]. Hydroxyl radical ( $\mathrm{OH})$ produced under aerobic condition by Fenton-like reactions from $\mathrm{H}_{2} \mathrm{O}_{2}$ with the help of ascorbic acid-Cu ${ }^{2+}$ could quench the florescence of C-rich DNA-template AuNCs in water and blood samples [105•].

Lead $\left(\mathrm{Pb}^{2+}\right)$ is a non-degradable toxic heavy metal pollutant that is commonly present in natural water sources as well as added by industrial waste to water. ssDNA-AgNC possesses green fluorescence that is converted to red emission on formation of duplex by the binding of complementary DNA strand. Water and human serum test samples containing $\mathrm{Pb}^{2+}$ induce $\mathrm{Pb}^{2+}$-dependent DNAzyme cleavage activity switching fluorescence back to green [106]. $\mathrm{Pb}^{2+}$-dependent DNAzyme was adsorbed on the surface of the nanoporous modified electrode that formed duplex with complementary DNA-AuNPs. AuNPs provide more space for the attachment of electroactive hexaammineruthenium(III) chloride molecules that generate current and were measured using chronocoulometry. $\mathrm{Pb}^{2+}$ present in the tap water, river water, and landfill leachate sample activates DNAzyme to release aptamer-AuNPs off the electrode surface leading to the decrease in charge [107]. A multiplexed $\mathrm{Pb}^{2+}$ and $\mathrm{Cu}^{2+}$ detection using QD-labeled DNAzymes is shown in Fig. 7.

Binding of dsDNA containing aptamer and complementary DNA probe prevents salt-induced aggregation of AuNPs in solution containing exonuclease I as the exonuclease I can degrade ssDNA only. Aptamer binds with $\mathrm{Pb}^{2+}$ present in test sample and exonuclease I degrades the second strand. This induces aggregation of AuNPs and is visualized by change in the color of solution from red to purple [89]. DNA-AuNP nanosensor has also been used for the detection of multiple metal ions simultaneously. The binding of metal ions on specific FAM-labeled DNA-AuNPs induces fluorescence quenching. Further to increase the specificity of the system, hydroxylamine and tetrachloroauric acid were added leading to diversification of morphologies of AuNPs depending upon the sequence of aptamer used. The variation in morphology of AuNPs was evident from appearance of different colors. The sensor could specifically detect $\mathrm{Ag}^{+}, \mathrm{Cd}^{2+}, \mathrm{Cu}^{2+}, \mathrm{Hg}^{2+}, \mathrm{Pb}^{2+}$, $\mathrm{Zn}^{2+}, \mathrm{Mn}^{2+}, \mathrm{Cr}^{3+}$, and $\mathrm{Sn}^{4+}$ in wastewater samples [99]. Metal ion detection using DNA nanosensor is comparatively well explored. It is a useful tool to detect heavy metals in various environmental samples. Strategies to design and use DNA template-based fluorescent nanoclusters for metal ion sensing in the environmental and biological sample have been discussed in detail elsewhere [34]. Existing nanosensor for metal ion have high sensitivity, but most of the sensor require complex experimental procedures and are not free from use of costly toxic reagent.

\section{Detection of Other Toxic Pollutants}

DNA nanosensor-based detection of contaminant dyes, explosives, and toxins has also been reported. Fluorogenic Rhodamine B dye entrapped in the pores of MSN is gated by aptamer. Bisphenol A present in the tap water samples binds to aptamer to release dye that creates fluorescence signal [109]. Dopamine can induce fluorescence quenching of dsDNA-CuNPs by photo-induced electron transfer process with CuNPs [118]. dsDNA template containing AgNPs releases DNA that become available to intercalating dye GeneFinder if dopamine is present in the test sample to produce fluorescence [119]. Large ssDNA holds two small complementary DNA strands, one side holds scaffold containing luminescent acceptor AgNCs and other side has site for holding $\pi$-donor 6-hydroxy-1-DOPA to form donor-acceptor pair. In the presence of explosives, contaminants, picric acid, trinitrotoluene, and hexahydro-1,3,5-trinitro-1,3,5-triazine (RDX), these bind to donor site as preferable acceptor leading to fluorescence quenching [120••]. Cyanide can bind and quench the fluorescence of AgNCs containing G-rich DNA sequence in river water sample [121]. Carbon nanotubes, graphene, metal, and metal oxide NP-based optical and electrochemical sensors for mycotoxin detection have been reviewed in detail earlier [131••]. Carbon dot-based DNA nanosensor has been used for detection of mutagenic nitrosamines, namely $N$-nitrosodimethylamine and $N$ nitrosodiethanolamine. Chitosan carbon dot-modified glassy carbon electrode immobilized with DNA undergoes change in 
Fig. 7 Schematic representation of QD-based catalytic

DNAzymes. The ZnS-capped CdSe QD is embedded in a siloxane shell and covalently coupled to DNAzymes. Each DNAzyme is composed of two quenchers. In the absence of the target metal ions, the fluorescence from the QD is quenched. Once the target metal ion binds to the DNAzyme, the fluorescence from the QD is restored due to the cleavage of the DNAzyme substrate. Reproduced with permission from $\mathrm{Wu}$ et al., American Chemical Society [113]

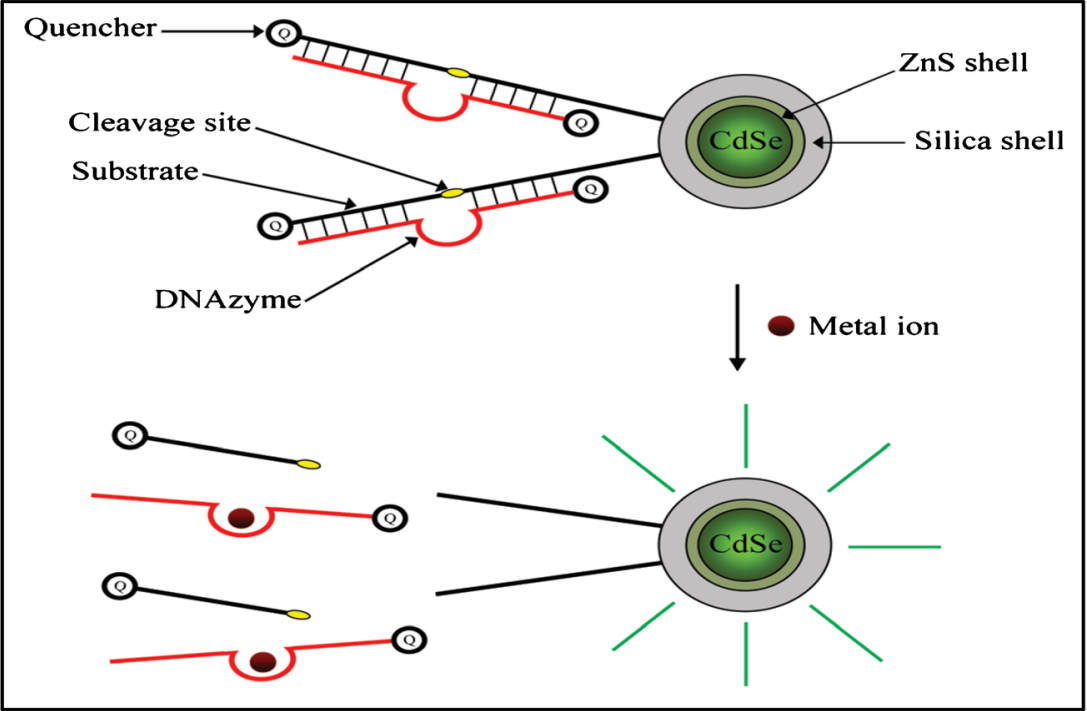

differential pulse voltammetry peak current in presence of nitrosamines [132] (Fig. 8).

\section{Practical Application of Nanosensors and Future Prospective}

AuNP-based DNA nanosensors have been used for the direct colorimetric detection of Mycobacterium tuberculosis in clinical samples. This method is inexpensive as compared to other two molecular US Food and Drug Administration approved methods for direct M. tuberculosis detection [133]. Peptide nucleic acid and DNA/RNA-functionalized NPs have been used for detection of the SARS-CoV-2 (COVID 19) using plasmonic colorimetric, localized surface plasmon resonance, and plasmonic photothermal technique-based approach [134]. DNA nanoswitches have been designed to detect highly infectious pathogenic zika virus and SARS-CoV-2 viruses in saliva samples [135] (Fig. 9).

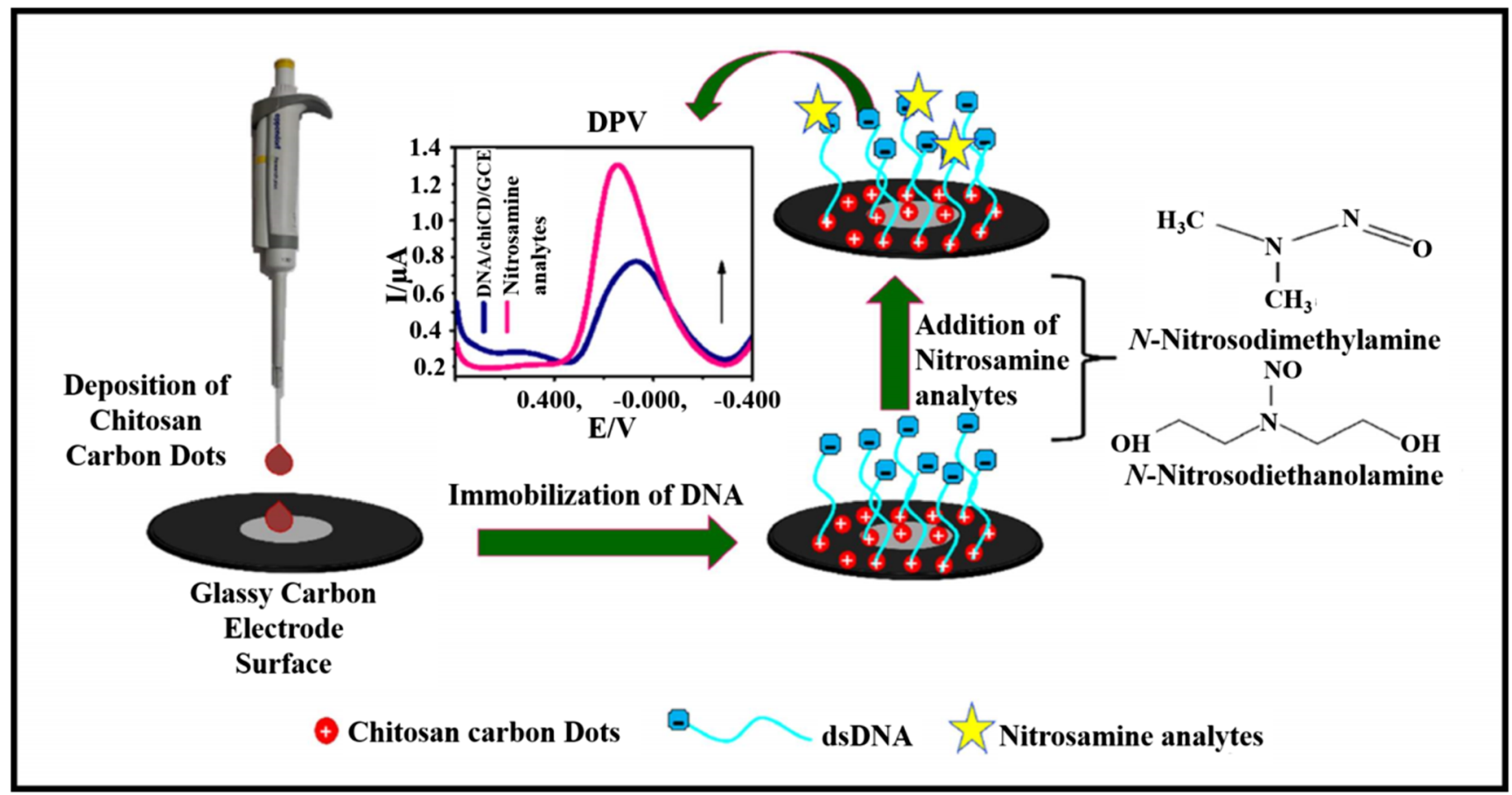

Fig. 8 Schematic representation of the process of fabricating modified electrode and subsequent detection of nitrosamine. Reproduced with permission from Majumdar et al., American Chemical Society [132] 


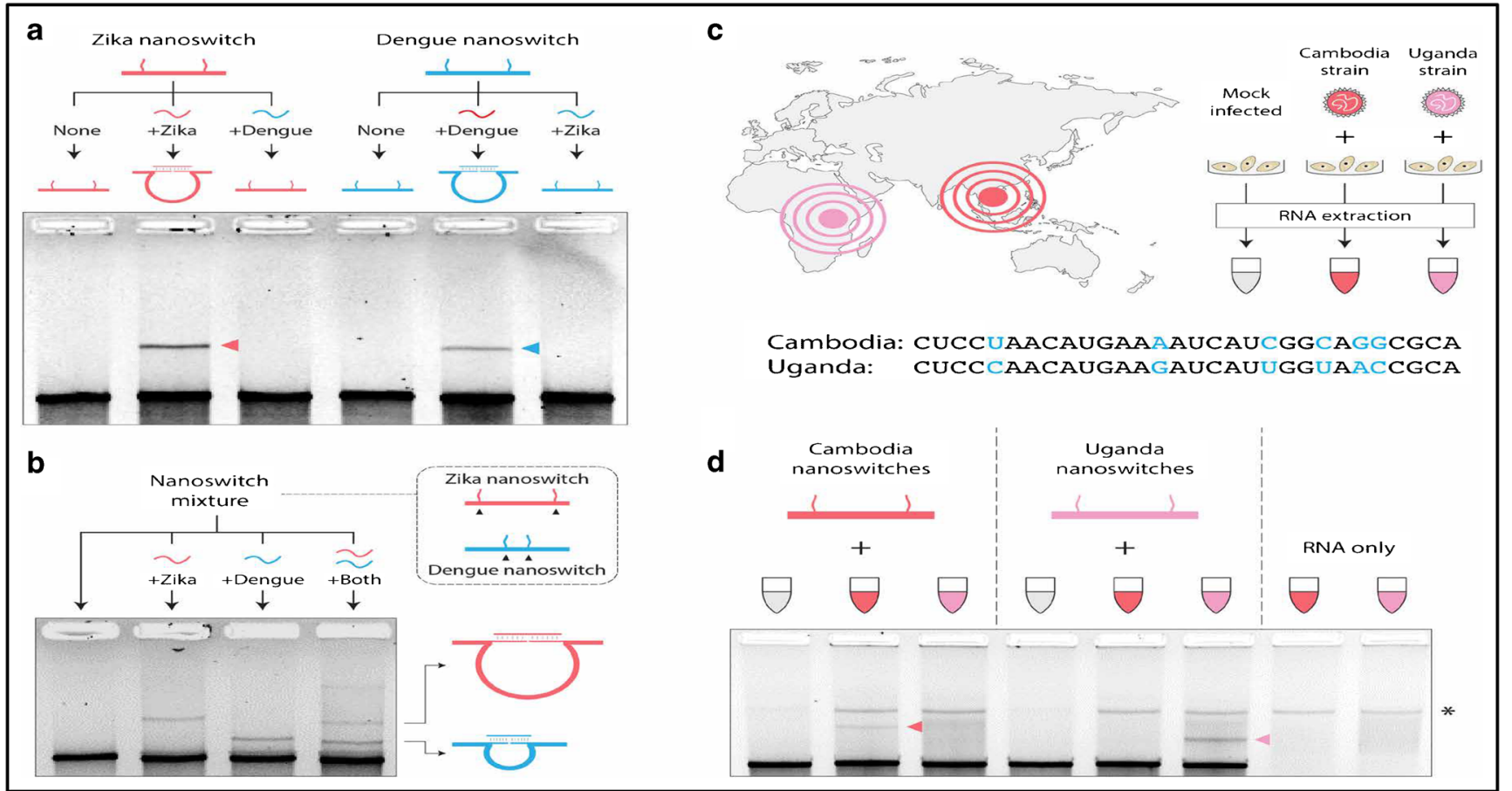

Fig. 9 DNA nanoswitches specifically and differentially detect RNA from two different flaviviruses and between two highly similar ZIKV isolates. a Zika virus (ZIKV) nanoswitches specifically detect ZIKV RNA but not dengue virus (DENV) RNA, and vice versa. b Multiplexed detection of ZIKV and DENV RNA. c Illustration showing culture and RNA extraction of ZIKV Cambodia and Uganda strains. The mismatches in a representative target sequence between the two strains are shown. d Specificity test of Cambodia and Uganda strains of ZIKV RNA. The asterisk denotes a band of contaminating cellular DNA following RNA isolation. Reproduced with permission from Zhou et al., American Association for the Advancement of Science [135]

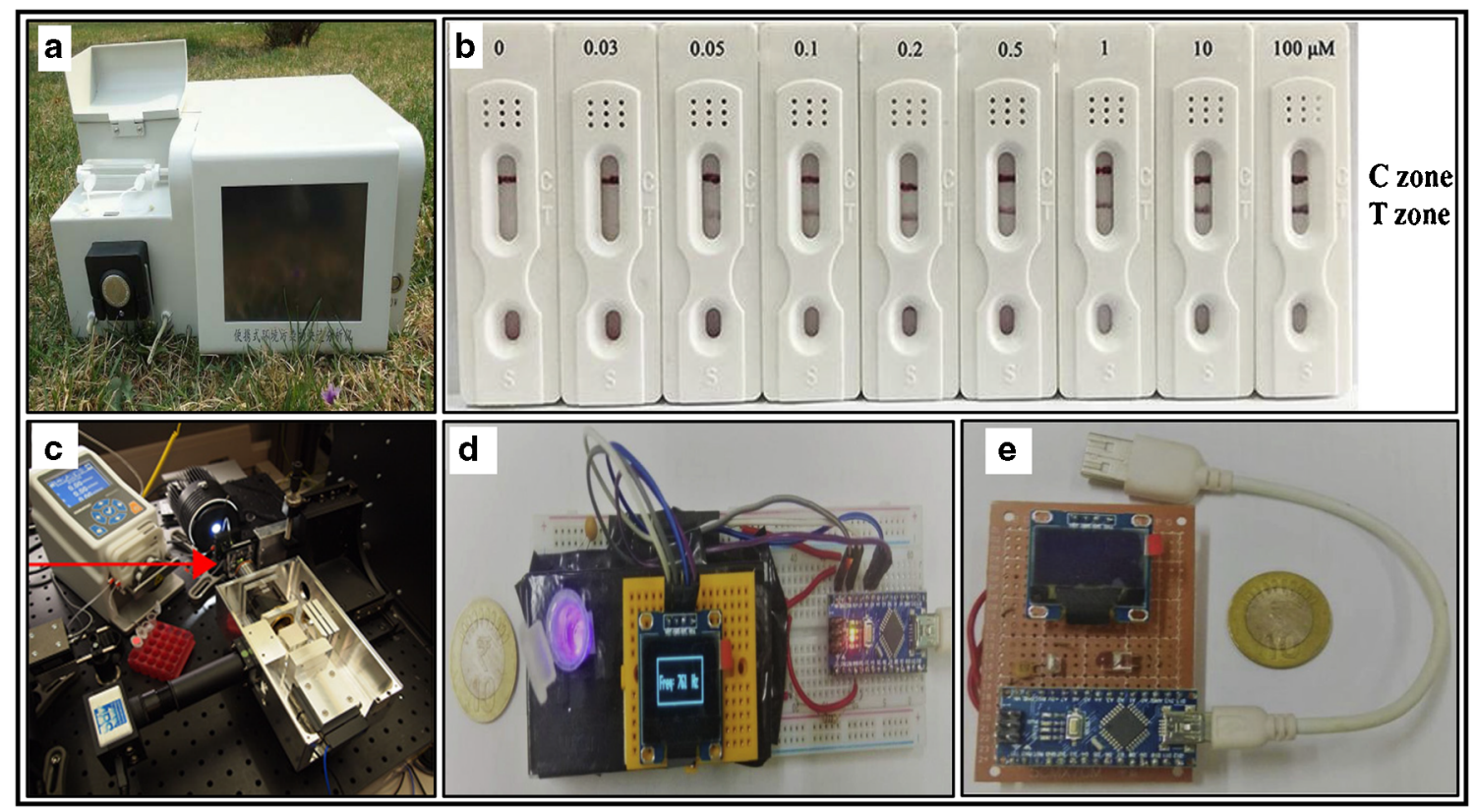

Fig. 10 a Photograph of the biosensing platform for the on-site/in situ detection of heavy metal ions (photo by Feng Long). Reproduced with permission, copyright Long et al., Springer Nature [140]. b Detection of kanamycin in milk samples. Reproduced with permission from $\mathrm{Ou}$ et al., Elsevier [47]. c Fourier transform imaging spectrometer used to measure response of DNA-modified gold NP-based plasmonic nanosensor upon interaction with fungal pathogen. Plasmonic microarrays are integrated in a microfluidic chamber. Reproduced with permission from Zopf et al., American Chemical Society [83]. d Handheld device developed for the detection of $\mathrm{Hg}^{2+}$, using aptamer-templated $\mathrm{ZnO}$ QDs. Breadboard-based detection prototype compared with a Rupee (INR) coin. e Miniaturized prototype. Reproduced with permission from Daniel et al., Elsevier [141] 
Detection of pork meat adulteration in meat product is a challenge in certain Asian and European countries. AuNPs functionalized with ssDNA probe specific for pork ssDNA can protect AuNPs from salt-induced aggregation in the absence of pork meat. In case of pork adulteration of meatball formulations, the probe ssDNA binds to pork ssDNA, thus inducing aggregation and color change in the presence of salt [136]. AuNPs containing ssDNA probe specific for horse cytochrome ssDNA gene can be used to detect horse meat adulteration in bovine meat products. The presence of horse meat avoids acid-induced aggregation of AuNPs as it is protected by dsDNA formed by horse cytochrome ssDNA binding to probe and AuNPs appear pink. In the absence of horse meat, the AuNPs appear purple due to acid-induced aggregation as ssDNA fails to protect AuNPs [137]. DNA-functionalized AuNPs are useful for detection of genotoxic, 2-anthramine, acridine orange, and 2-naphthylamine in water samples from Henan province, China [138]. DNA-functionalized AuNPs have been used for the sensing of kanamycin in honey, milk, and milk powder samples [47]. Probe-functionalized $\mathrm{Au}$ core-Au shell NPs have been used for the kanamycin detection in milk samples [139]. Various types of nanodevices are designed for the industrial-scale application as shown in Fig. 10.

Global environmental monitoring market has worth USD 14 billion in 2020 . The market is growing due to continuous rise in global pollution and expected to have value of USD 17.1 billion by $2025[142,143]$. Spanish startup NT Sensors, Italian startup Nasys, Israel-based startup Tracense, and USbased startups Razzberry and nGageIT are top nanosensor startups. The compound annual growth rate of nanosensor was USD 208 million in 2017. It is expected to reach USD 1192.25 million with $33.73 \%$ growth in 2023. In spite of current global economic challenges, the compound annual growth rate of nanosensor in global market has been estimated to increase by $10 \%$ by 2025 . Nanosensors are digitalized with recent technology that makes them accurate but sometimes difficult for patient to operate at its own in a remote place $[142,144]$. So, designing nanosensors that are reliable and easy to operate by patient at remote place is a challenging task. More robust and user-friendly DNA nanosensor needs to be designed for various environmental applications.

\section{Conclusions}

DNA nanosensors are useful for easy and cost-effective detection of pathogens, antibiotics, pesticides, GMO, and other environmental pollutants. DNA nanosensors are comparatively less explored for pathogenic virus and fungus detection. There is huge scope for detection of unexplored GMO, antibiotics, and pesticides using DNA nanosensor. The specificity, ease of designing, and cost-effectiveness of DNA-based nanosensor are main features making them useful for detection of diverse analytes even in complex medium in the future as well.

Acknowledgments VK is thankful to LPU and PG is thankful to DAVU for encouragement and support to carry out this research.

\section{Compliance with Ethical Standards}

Conflict of Interest The authors declare that they have no conflicts of interest.

Human and Animal Rights and Informed Consent This article does not contain any studies with human or animal subjects performed by any of the authors.

\section{References}

Papers of particular interest, published recently, have been highlighted as:

- Of importance

•- Of major importance

1. Gruber K. Cleaning up our future health. Nature. 2018;555(7695): S20-2.

2. Pellizzari ED, Woodruff TJ, Boyles RR, Kannan K, Beamer PI, Buckley JP, et al. Identifying and prioritizing chemicals with uncertain burden of exposure: opportunities for biomonitoring and health-related research. Environ Health Perspect. 2019;127(12): 126001.

3. Shaffer RM, Sellers SP, Baker MG, de Buen KR, Frostad J, Suter $\mathrm{MK}$, et al. Improving and expanding estimates of the global burden of disease due to environmental health risk factors. Environ Health Perspect. 2019;127(10):105001.

4. Cardona B, Rudel RA. US EPA's regulatory pesticide evaluations need clearer guidelines for considering mammary gland tumors and other mammary gland effects. Mol Cell Endocrinol. 2020;7: 110927.

5. Ahmed S, Siddique MA, Rahman M, Bari ML, Ferdousi S. A study on the prevalence of heavy metals, pesticides, and microbial contaminants and antibiotics resistance pathogens in raw salad vegetables sold in Dhaka, Bangladesh. Heliyon. 2019;5(2): e01205.

6. Pingali PL. Green revolution: impacts, limits, and the path ahead. Proc Natl Acad Sci. 2012;109(31):12302-8.

7. Duhan JS, Kumar R, Kumar N, Kaur P, Nehra K, Duhan S. Nanotechnology: the new perspective in precision agriculture. Biotechnol Rep. 2017;15:11-23.

8. Guleria P., Kumar V. 2018. Impact of Recombinant DNA Technology and Nanotechnology on Agriculture. In: Lichtfouse E, editor. Sustainable Agriculture Reviews 32. Sustainable Agriculture Reviews. Cham: Springer; 2018. p. 271-292. https://doi.org/10.1007/978-3-319-98914-3_11. This review offers a thorough, up-to-date discussion of effect of two recent techniques recombinant DNA and nanotechnology on agricultural crops, as well as valuable insights into the challenges and future of these techniques.

9. Park SR, Yoon YJ, Pham JV, Yilma MA, Feliz A, Majid MT, et al. A review of the microbial production of bioactive natural products and biologics. Front Microbiol. 2019;10:1404 This article 
reviews advances in use of genetically engineered microorganism for industrial-scale production of various key products.

10. Tchounwou PB, Yedjou CG, Patlolla AK, Sutton DJ. Heavy metal toxicity and the environment. In Molecular, clinical and environmental toxicology, (pp. 133-164). Springer, Basel. 2012.

11. Vogel V. Nanosensors and particles: a technology frontier with pitfalls. J Nanobiotechnol. 2019;17(1):111 This article reviews the safety concerns of nanomaterials used in designing nanosensor. It highlights the need of use of safe nanomaterials as the production of nanomaterials for various applications is exponentially increasing.

12.•v van Zee RD, Pomrenke GS, Evans HM. Nanotechnology-enabled sensing: report of the National Nanotechnology Initiative Workshop, Held in Arlington, Virginia on May 5-7, 2009. Arlington: National Nanotechnology Coordination Office; 2009.

This report highlights the drawback of routine analytical methods and usefulness of nanomaterials in pollutant detection reducing bias in analysis as a result of handling

13. Devreese JT. Importance of nanosensors: Feynman's vision and the birth of nanotechnology. MRS Bull. 2007;32(9):718-25.

14. Fadel TR, Farrell DF, Friedersdorf LE, Griep MH, Hoover MD, Meador MA, et al. Toward the responsible development and commercialization of sensor nanotechnologies. ACS Sens. 2016;1(3): 207-16.

15.•• Harroun SG, Prévost-Tremblay C, Lauzon D, Desrosiers A, Wang X, Pedro L, et al. Programmable DNA switches and their applications. Nanoscale. 2018;10(10):4607-41 This review describes the designing, binging dynamics of DNA switches for sensing, drug delivery, smart materials, molecular transporters, logic gates, and others.

16. Qin X, Yin Y, Yu H, Guo W, Pei M. A novel signal amplification strategy of an electrochemical aptasensor for kanamycin, based on thionine functionalized graphene and hierarchical nanoporous $\mathrm{PtCu}$. Biosens Bioelectron. 2016;77:752-8.

17. Narmani A, Kamali M, Amini B, Kooshki H, Amini A, Hasani L. Highly sensitive and accurate detection of Vibrio cholera O1 OmpW gene by fluorescence DNA biosensor based on gold and magnetic nanoparticles. Process Biochem. 2018;65:46-54.

18. Oroval M, Coll C, Bernardos A, Marcos MD, Martínez-Máñez R, Shchukin DG, et al. Selective fluorogenic sensing of As (III) using aptamer-capped nanomaterials. ACS Appl Mater Interfaces. 2017;9(13):11332-6.

19. Zhang C, Chen Y, Liang X, Zhang G, Ma H, Nie L, et al. Detection of hepatitis B virus M204I mutation by quantum dotlabeled DNA probe. Sensors. 2017;17(5):961.

20. Chang F, Huang L, Guo C, Xie G, Li J, Diao Q. Graphdiyne-based one-step DNA fluorescent sensing platform for the detection of Mycobacterium tuberculosis and its drug-resistant genes. ACS Appl Mater Interfaces. 2019;11(39):35622-9.

21. Li Z, Liu R, Xing G, Wang T, Liu S. A novel fluorometric and colorimetric sensor for iodide determination using DNA-templated gold/silver nanoclusters. Biosens Bioelectron. 2017a;96: 44-8.

22. Willner MR, Vikesland PJ. Nanomaterial enabled sensors for environmental contaminants. J Nanobiotechnol. 2018;16(1):1-6.

23. Li S, Wu X, Liu C, Yin G, Luo J, Xu Z. Application of DNA aptamers as sensing layers for detection of carbofuran by electrogenerated chemiluminescence energy transfer. Anal Chim Acta. 2016;941:94-100.

24. Chen T, Wang H, Wang Z, Tan M. Construction of time-resolved luminescence nanoprobe and its application in As (III) detection. Nanomaterials. 2020;10(3):551.

25. Banerjee T, Tummala T, Elliott R, Jain V, Brantley W, Hadorn L, et al. Multimodal magneto-fluorescent nanosensor for rapid and specific detection of blood-borne pathogens. ACS Appl Nano Mater. 2019;2(9):5587-93.
26. Wang Z, Lu Q, Xu T, Wang F, Huang F, Peng Y, et al. Gquadruplex-based assay combined with aptamer and gold nanoparticles for Escherichia coli K88 determination. Microchim Acta. 2020a;187:1-9 This article describes how intestinal pathogen $E$. coli $K 88$ selectively binds to specifically designed aptamer and induces G-quadruplex-based aggregation of AuNPs as visualized using color change as well as spectrophotometer.

27.• Wang JC, Tung YC, Ichiki K, Sakamoto H, Yang TH, Suye SI, et al. Culture-free detection of methicillin-resistant Staphylococcus aureus by using self-driving diffusometric DNA nanosensors. Biosens Bioelectron. 2020b;148:111817 This article discusses simple decrease in diffusivity of AuNP-nanobeads as a result of sandwich complex formation only in presence of MRSA.

28. Kumar V, Dasgupta N, Ranjan S, editors. Nanotoxicology: toxicity evaluation, risk assessment and management. Boca Raton: CRC Press; 2018. This book highlights the need, procedure, and strategies for toxicity assessment and management of various types of nanomaterials in detail.

29. Alahi ME, Mukhopadhyay SC. Detection methodologies for pathogen and toxins: a review. Sensors. 2017;17(8):1885.

30. Meng J, Doyle MP. Introduction. Microbiological food safety. Microbes Infect. 2002;4(4):395-7.

31. Mandal PK, Biswas AK, Choi K, Pal UK. Methods for rapid detection of foodborne pathogens: an overview. Am J Food Technol. 2011;6(2):87-102.

32. Zhang G. Foodborne pathogenic bacteria detection: an evaluation of current and developing methods. Meducator. 2013;6(24):1.

33. Pérez-López B, Merkoçi A. Nanomaterials based biosensors for food analysis applications. Trends Food Sci Technol. 2011;22(11):625-39.

34. Song C, Xu J, Chen Y, Zhang L, Lu Y, Qing Z. DNA-templated fluorescent nanoclusters for metal ions detection. Molecules. 2019;24(22):4189.

35. Jyoti A, Singh SP, Yashpal M, Dwivedi PD, Shanker R. Rapid detection of enterotoxigenic Escherichia coli gene using bio-conjugated gold nano-particles. J Biomed Nanotechnol. 2011;7(1): $170-1$.

36. Jamdagni P, Khatri P, Rana JS. Nanoparticles based DNA conjugates for detection of pathogenic microorganisms. Int Nano Lett. 2016;6(3):139-46.

37. Mokhtarzadeh A, Eivazzadeh-Keihan R, Pashazadeh P, Hejazi M, Gharaatifar N, Hasanzadeh M, et al. Nanomaterial-based biosensors for detection of pathogenic virus. TrAC Trends Anal Chem. 2017;97:445-57.

38. Zhou X, Wang L, Shen G, Zhang D, Xie J, Mamut A, et al. Colorimetric determination of ofloxacin using unmodified aptamers and the aggregation of gold nanoparticles. Microchim Acta. 2018;185(7):355.

39. Emrani AS, Danesh NM, Lavaee P, Ramezani M, Abnous K, Taghdisi SM. Colorimetric and fluorescence quenching aptasensors for detection of streptomycin in blood serum and milk based on double-stranded DNA and gold nanoparticles. Food Chem. 2016;190:115-21.

40. Ramezani M., Abnous K., Taghdisi S.M. 2017. Optical and Electrochemical Aptasensors for Sensitive Detection of Streptomycin in Blood Serum and Milk. In: Prickril B., Rasooly A. (editors). Biosensors and Biodetection. Methods in Molecular Biology. New York: Humana Press; 2017. p. 403-420.

41. Ribes A, Santiago-Felipe S, Bernardos A, Marcos MD, Pardo T, Sancenón F, et al. Two new fluorogenic aptasensors based on capped mesoporous silica nanoparticles to detect ochratoxin A. ChemistryOpen. 2017a;6(5):653-9.

42. Liu S, Wang Y, Xu W, Leng X, Wang H, Guo Y, et al. A novel sandwich-type electrochemical aptasensor based on GR-3D Au 
and aptamer-AuNPs-HRP for sensitive detection of oxytetracycline. Biosens Bioelectron. 2017;88:181-7.

43.• Zhu C, Liu D, Chen Z, Li L, You T. An ultra-sensitive aptasensor based on carbon nanohorns/gold nanoparticles composites for impedimetric detection of carbendazim at picogram levels. J Colloid Interface Sci. 2019;546:92-100 This article reports easy and picomolar level sensitive carbendazim detection using simple approach of increase in impedance upon carbendazim binding to aptamer-AuNP-modified electrode.

44. Liu BW, Wu YY, Huang PC, Wu FY. Colorimetric determination of cytosine-rich ssDNA by silver (I)-modulated glucose oxidasecatalyzed growth of gold nanoparticles. Microchim Acta. $2019 \mathrm{Jul}$ 1;186(7):467.

45. Rapini R, Marrazza G. Electrochemical aptasensors for contaminants detection in food and environment: recent advances. Bioelectrochemistry. 2017a;118:47-61 This review gives broad overview of functioning of electrochemical nanosensor used for food and environmental contaminant detection.

46. Liu J, Zeng J, Tian Y, Zhou N. An aptamer and functionalized nanoparticle-based strip biosensor for on-site detection of kanamycin in food samples. Analyst. 2018;143(1):182-9.

47. Ou Y, Jin X, Liu J, Tian Y, Zhou N. Visual detection of kanamycin with DNA-functionalized gold nanoparticles probe in aptamerbased strip biosensor. Anal Biochem. 2019;587:113432.

48. $\mathrm{Xu} \mathrm{C}$, Ying Y, Ping J. Colorimetric aggregation assay for kanamycin using gold nanoparticles modified with hairpin DNA probes and hybridization chain reaction-assisted amplification. Microchim Acta. 2019;186(7):448.

49. Zhang K, Cao J, Wu Y, Hu F, Li T, Wang Y, et al. A fluorometric aptamer method for kanamycin by applying a dual amplification strategy and using double Y-shaped DNA probes on a gold bar and on magnetite nanoparticles. Microchim Acta. 2019a;186(2): 120 This article describes a novel florescence-based strategy in which kanamycin is binding to $\mathrm{Y}$-shaped DNA that triggers its conversion to hairpin-like structure that favors formation of elongated dsDNA by incorporating fluorescent dye.

50. Hong CY, Zhang XX, Dai CY, Wu CY, Huang ZY. Highly sensitive detection of multiple antibiotics based on DNA tetrahedron 1030 nanostructure-functionalized magnetic beads. Anal Chim Acta. 2020; 1120:50-8

51. Muenchen DK, Martinazzo J, de Cezaro AM, Rigo AA, Brezolin AN, Manzoli A, et al. Pesticide detection in soil using biosensors and nanobiosensors. Biointerf Res Appl Chem. 2016;6(6):165975.

52. Zhang H, West D, Shi H, Ma Y, Adams C, Eichholz T. Simultaneous determination of selected trace contaminants in drinking water using solid-phase extraction-high performance liquid chromatography-tandem mass spectrometry. Water Air Soil Pollut. 2019;230:28.

53. Kaur R, Kaur R, Rani S, Malik AK, Kabir A, Furton KG. Application of fabric phase sorptive extraction with gas chromatography and mass spectrometry for the determination of organophosphorus pesticides in selected vegetable samples. J Sep Sci. 2019;42:862-70

54. Song L, Han Y, Yang J, Qin Y, Zeng W, Xu S, et al. Rapid singlestep cleanup method for analyzing 47 pesticide residues in pepper, chili peppers and its sauce product by high performance liquid and gas chromatography-tandem mass spectrometry. Food Chem. 2019;279:237-45.

55. Della PF, Angelini C, Sergi M, Del Carlo M, Pepe A, Compagnone D. Nano carbon black-based screen printed sensor for carbofuran, isoprocarb, carbaryl and fenobucarb detection: application to grain samples. Talanta. 2018;186:389-96.

56. Montes R, Céspedes F, Gabriel D, Baeza M. Electrochemical biosensor based on optimized biocomposite for organophosphorus and carbamates pesticides detection. J Nanomater. 2018;2018:1-13.

57. Gholivand M-B, Akbari A, Norouzi L, Norozi L. Development of a novel hollow fiber-pencil graphite modified electrochemical sensor for the ultra-trace analysis of glyphosate. Sensors Actuators B Chem. 2018;272:415-24.

58. Dai Y, Wang T, Hu X, Liu S, Zhang M, Wang C. Highly sensitive microcantilever-based immunosensor for the detection of carbofuran in soil and vegetable samples. Food Chem. 2017;229:432-8

59. Su M, Jia L, Wu X, Sun H. Residue investigation of some phenylureas and tebuthiuron herbicides in vegetables by ultra-performance liquid chromatography coupled with integrated selective accelerated solvent extraction-clean up in situ. J Sci Food Agric. 2018;98:4845-53.

60. Guo Y, Liu R, Liu Y, Xiang D, Liu Y, Gui W, et al. A noncompetitive surface plasmon resonance immunosensor for rapid detection of triazophos residue in environmental and agricultural samples. Sci Total Environ. 2018;613:783-91.

61. Ghoto A, Khuhawar MY, Janhngir TM. Silver nanoparticles with sodium dodecyl sulfate as colorimetric probe for detection of dithiocarbamate pesticides in environmental samples. Anal Sci. 2019;35:631-7.

62. Fahimi-Kashani N, Hormozi-Nezhad MR. Gold nanoparticlebased colorimetric sensor array for discrimination of organophosphate pesticides. Anal Chem. 2016;88:8099-106.

63. March C, Manclús J, Jiménez Y, Arnau A, Montoya A. A piezoelectric immunosensor for the determination of pesticide residues and metabolites in fruit juices. Talanta. 2009;78:827-33.

64. Wang J-J, Liu W-H, Chen D, Xu Y, Zhang L-Y. A micro-machined thin film electro-acoustic biosensor for detection of pesticide residuals. J Zhejiang Univ Sci C. 2014;15:383-9.

65. Miao SS, Wu MS, Ma LY, He XJ, Yang H. Electrochemiluminescence biosensor for determination of organophosphorous pesticides based on bimetallic Pt-Au/multi-walled carbon nanotubes modified electrode. Talanta. 2016;158:14251.

66. Yang L, Zhang X, Wang J, Sun H, Jiang L. Double-decrease of the fluorescence of $\mathrm{CdSe} / \mathrm{ZnS}$ quantum dots for the detection of zinc(II) dimethyldithiocarbamate (ziram) based on its interaction with gold nanoparticles. Microchim Acta. 2018;185:472.

67. Zakery M, Ensafi AA, Rezaei B. A novel optosensor for rapid detection of difenoconazole using molecularly imprinted polymers. IEEE Sensors J. 2018;18:9466-70.

68. Gosset A, Durrieu C, Renaud L, Deman A-L, Barbe P, Bayard R, et al. Xurography-based microfluidic algal biosensor and dedicated portable measurement station for online monitoring of urban polluted samples. Biosens Bioelectron. 2018;117:669-77.

69. Liu S, Zheng Z, Li X. Advances in pesticide biosensors: current status, challenges, and future perspectives. Anal Bioanal Chem. 2013;405(1):63-90.

70. Yang L, Sun H, Wang X, Yao W, Zhang W, Jiang L. An aptamer based aggregation assay for the neonicotinoid insecticide acetamiprid using fluorescent upconversion nanoparticles and DNA functionalized gold nanoparticles. Microchim Acta. 2019;186(5):308.

71. Guo J, Li Y, Wang L, Xu J, Huang Y, Luo Y, et al. Aptamer-based fluorescent screening assay for acetamiprid via inner filter effect of gold nanoparticles on the fluorescence of CdTe quantum dots. Anal Bioanal Chem. 2016;408(2):557

72. Jiang D, Du X, Liu Q, Zhou L, Dai L, Qian J, et al. Silver nanoparticles anchored on nitrogen-doped graphene as a novel electrochemical biosensing platform with enhanced sensitivity for aptamer-based pesticide assay. Analyst. 2015;140(18):6404-11.

73.• Fei A, Liu Q, Huan J, Qian J, Dong X, Qiu B, et al. Label-free impedimetric aptasensor for detection of femtomole level 
acetamiprid using gold nanoparticles decorated multiwalled carbon nanotube-reduced graphene oxide nanoribbon composites. Biosens Bioelectron. 2015;70:122-9 This article describes the simple approach of change in parameters as a result of acetamiprid binding to electrode modified with aptamer functionalized nanocomposite.

74. Li X, Shi J, Chen C, Li W, Han L, Lan L, et al. One-step, visual and sensitive detection of phorate in blood based on a DNAAgNC aptasensor. New J Chem. 2018;42(8):6293-8.

75.• Jokar M, Safaralizadeh MH, Hadizadeh F, Rahmani F, Kalani MR. Design and evaluation of an apta-nano-sensor to detect Acetamiprid in vitro and in silico. J Biomol Struct Dyn. 2016;34(11):2505-17 This article discusses use of bioinformatic software as screening tool to determine the in vitro experimental condition, and acetamiprid induces aggregation of ssDNA-AgNPs by salt leading to visible color change.

76. Selvolini G, Băjan I, Hosu O, Cristea C, Săndulescu R, Marrazza G. DNA-based sensor for the detection of an organophosphorus pesticide: profenofos. Sensors. 2018;18(7):2035.

77. Viswanathan S, Radecka H, Radecki J. Electrochemical biosensor for pesticides based on acetylcholinesterase immobilized on polyaniline deposited on vertically assembled carbon nanotubes wrapped with ssDNA. Biosens Bioelectron. 2009;24(9):2772-7.

78. Nobukawa A, Osaki T, Tonooka T, Morimoto Y, Takeuchi S. Electrical detection of pesticide vapors by biological nanopores with DNA aptamers. In: 28th IEEE International Conference on Micro Electro Mechanical Systems (MEMS) 2015 Jan 18 (pp. 596-599). IEEE.

79. Du P, Jin M, Zhang C, Chen G, Cui X, Zhang Y, et al. Highly sensitive detection of triazophos pesticide using a novel bio-barcode amplification competitive immunoassay in a micro well plate-based platform. Sensors Actuators B Chem. 2018;256: 457-64.

80.• Zhang X, Du P, Cui X, Chen G, Wang Y, Zhang Y, et al. A sensitive fluorometric bio-barcodes immunoassay for detection of triazophos residue in agricultural products and water samples by iterative cycles of DNA-RNA hybridization and dissociation of fluorophores by Ribonuclease H. Sci Total Environ. 2020;717: 137268 This article discusses triazophos-induced revival of fluorescence by removal of fluorophores from fluorophoreRNA-AuNP-ssDNA complex fixed on a plate.

81. Fan Y, Cui M, Liu Y, Jin M, Zhao H. Selection and characterization of DNA aptamers for constructing colorimetric biosensor for detection of PBP2a. Spectrochim Acta A Mol Biomol Spectrosc. 2020;228:117735.

82. Bai L, Chen Y, Liu X, Zhou J, Cao J, Hou L, et al. Ultrasensitive electrochemical detection of Mycobacterium tuberculosis IS6110 fragment using gold nanoparticles decorated fullerene nanoparticles/nitrogen-doped graphene nanosheet as signal tags. Anal Chim Acta. 2019;1080:75-83.

83. Zopf D, Pittner A, Dathe A, Grosse N, Csáki A, Arstila K, et al. Plasmonic nanosensor array for multiplexed DNA-based pathogen detection. ACS Sens. 2019;4(2):335-43.

84. Li Y, Hao N, Luo S, Liu Q, Sun L, Qian J, et al. Simultaneous detection of TNOS and P35S in transgenic soybean based on magnetic bicolor fluorescent probes. Talanta. 2020;212:120764.

85. Chen D, Zhang M, Ma M, Hai H, Li J, Shan Y. A novel electrochemical DNA biosensor for transgenic soybean detection based on triple signal amplification. Anal Chim Acta. 2019 Oct 31;1078: 24-31.

86. Jang H, Kwak CH, Kim G, Kim SM, Huh YS, Jeon TJ. Identification of genetically modified DNA found in roundup ready soybean using gold nanoparticles. Microchim Acta. 2016;183(9):2649-54.

87. Cihalova K, Hegerova D, Dostalova S, Jelinkova P, Krejcova L, Milosavljevic V, et al. Particle-based immunochemical separation of methicillin resistant Staphylococcus aureus with indirect electrochemical detection of labeling oligonucleotides. Anal Methods. 2016;8(25):5123-8 This manuscript discusses strategy to design immunochemical separation-based detection of MRSA using antibodies specific for MRSA-specific plasmin-sensitive proteins encoding gene and magnetic NPs.

88.• Chen K, Han H, Luo Z, Wang Y, Wang X. A practicable detection system for genetically modified rice by SERS-barcoded nanosensors. Biosens Bioelectron. 2012;34(1):118-24 This article uses Bt gene-specific change in surface-enhanced Raman scattering signal as strategy to detect transgenic rice.

89. Shahdordizadeh M, Yazdian-Robati R, Ansari N, Ramezani M, Abnous K, Taghdisi SM. An aptamer-based colorimetric lead (II) assay based on the use of gold nanoparticles modified with dsDNA and exonuclease I. Microchim Acta. 2018;185(2):151.

90. Lv J, Miao Y, Yan G. Detection of specific DNA sequences in Maize (Zea mays L.) based on phosphorescent quantum-dot exciton energy transfer. New J Chem. 2019;43(14):5308-14 This article describes simple approach using CaMV 35S sequence of transgenic maize to induce aggregation of ssDNA-QDs that leads to reduction in phosphoresce intensity.

91. Watanabe K, Kuwata N, Sakamoto H, Amano Y, Satomura T, Suye SI. A smart DNA sensing system for detecting methicillinresistant Staphylococcus aureus using modified nanoparticle probes. Biosens Bioelectron. 2015;67:419-23.

92. Ning Y, Gao Q, Zhang X, Wei K, Chen L. A graphene oxidebased sensing platform for the determination of methicillin-resistant Staphylococcus aureus based on strand-displacement polymerization recycling and synchronous fluorescent signal amplification. J Biomol Screen. 2016;21(8):851-7.

93. Karimi F, Dabbagh S. Gel green fluorescence ssDNA aptasensor based on carbon nanotubes for detection of anthrax protective antigen. Int J Biol Macromol. 2019;140:842-50.

94.• Ye Y, Mao S, He S, Xu X, Cao X, Wei Z, et al. Ultrasensitive electrochemical genosensor for detection of CaMV35S gene with $\mathrm{Fe}_{3} \mathrm{O}_{4}$-Au@Ag nanoprobe. Talanta. 2020;206:120205 This article describes electrochemical nanosensor for the transgenic tomato detection using sandwich complex formation abilities of transgenic-specific sequence CaMV35S that leads to increase in current.

95. Sousa JB, Ramos-Jesus J, Silva LC, Pereira C, de-Los-SantosÁlvarez N, Fonseca RA, et al. $\mathrm{Fe}_{3} \mathrm{O}_{4} @$ Au nanoparticles-based magnetoplatform for the HMGA maize endogenous gene electrochemical genosensing. Talanta. 2020;206:120220.

96. Tchounwou PB, Yedjou CG, Patlolla AK, Sutton DJ. Heavy metal toxicity and the environment. Molecular, clinical and environmental toxicology. Basel: Springer; 2012. p. 133-64.

97. Wang G, Wang S, Yan C, Bai G, Liu Y. DNA-functionalized gold nanoparticle-based fluorescence polarization for the sensitive detection of silver ions. Colloids Surf B: Biointerfaces. 2018a;167: $150-5$.

98. Li A, Zhang J, Qiu J, Zhao Z, Wang C, Zhao C, et al. A novel aptameric biosensor based on the self-assembled DNA-WS2 nanosheet architecture. Talanta. 2017b Jan 15;163:78-84.

99.• Tan L, Chen Z, Zhao Y, Wei X, Li Y, Zhang C, et al. Dual channel sensor for detection and discrimination of heavy metal ions based on colorimetric and fluorescence response of the AuNPs-DNA conjugates. Biosens Bioelectron. 2016;85:414-21 This article describes simple fluorescence and colorimetric approach where particular metal ion induces fluorescence quenching of AuNPs labeled with specific DNA probe. Further growth of NPS is induced that lead to diverse morphologies depending upon the metal ion involved thus detected visibly by peculiar color. 
100. $\mathrm{Pu} \mathrm{W}$, Zhao Z, Wu L, Liu Y, Zhao H. Label-free detection of $\mathrm{Ag}^{+}$ based on gold nanoparticles and $\mathrm{Ag}^{+}$-specific DNA. J Nanosci Nanotechnol. 2015;15(8):5524-9.

101. Lee J, Park J, Lee HH, Park H, Kim HI, Kim WJ. Fluorescence switch for silver ion detection utilizing dimerization of DNA-Ag nanoclusters. Biosens Bioelectron. 2015;68:642-7 This article discusses how mismatched ssDNA can complex in presence of $\mathrm{Ag}^{+}$to induce change in fluorescence from red to green.

102. Yang Y, Zhang S, Kang M, He L, Zhao J, Zhang H, et al. Selective detection of silver ions using mushroom-like polyaniline and gold nanoparticle nanocomposite-based electrochemical DNA sensor. Anal Biochem. 2015;490:7-13.

103. Tan D, He Y, Xing X, Zhao Y, Tang H, Pang D. Aptamer functionalized gold nanoparticles based fluorescent probe for the detection of mercury (II) ion in aqueous solution. Talanta. 2013;113: 26-30.

104. Zhang Y, Zhang L, Wang L, Wang G, Komiyama M, Liang X. Colorimetric determination of mercury (II) ion based on DNAassisted amalgamation: a comparison study on gold, silver and Ag@au Nanoplates. Microchim Acta. 2019b;186(11):713.

105. Qing T, Bu H, He X, He D, Zhou B, Sun H, et al. A selective nanosensor for ultrafast detection of $\mathrm{Cu}^{2+}$ ions based on C5 DNAtemplated gold nanoclusters and Fenton-like reaction. Anal Methods. 2017;9(44):6222-7 This article describes $\mathrm{Cu}$ ionbased aerobic generation of OHthat leads to fluorescence quenching of nanomaterials.

106. Wang J, Zhang Z, Gao X, Lin X, Liu Y, Wang S. A single fluorophore ratiometric nanosensor based on dual-emission DNA-templated silver nanoclusters for ultrasensitive and selective $\mathrm{Pb}^{2+}$ detection. Sensors Actuators B Chem. 2019;282:712-8.

107. Zhang C, Lai C, Zeng G, Huang D, Tang L, Yang C, et al. Nanoporous Au-based chronocoulometric aptasensor for amplified detection of $\mathrm{Pb}^{2+}$ using DNAzyme modified with Au nanoparticles. Biosens Bioelectron. 2016;81:61-7.

108. Wu Y, Zhan S, Xing H, He L, Xu L, Zhou P. Nanoparticles assembled by aptamers and crystal violet for arsenic (III) detection in aqueous solution based on a resonance Rayleigh scattering spectral assay. Nanoscale. 2012;4(21):6841-9.

109. Ribes À, Aznar E, Bernardos A, Marcos MD, Amorós P, Martínez-Máñez R, et al. Fluorogenic sensing of carcinogenic bisphenol A using aptamer-capped mesoporous silica nanoparticles. Chem Eur J. 2017c;23(36):8581-4 This article reports easy bisphenol A-specific binding to aptamer and thus releasing fluorescent dye from silica NPs.

110. Wu Y, Lai RY. A reagentless DNA-based electrochemical silver (I) sensor for real time detection of $\mathrm{Ag}$ (I)-the effect of probe sequence and orientation on sensor response. Biotechnol J. 2016;11(6):788-96.

111. Ebrahimi M, Raoof JB, Ojani R. Novel electrochemical DNA hybridization biosensors for selective determination of silver ions. Talanta. 2015;144:619-26.

112. You J, Song Y, Park C, Jang K, Na S. A microcantilever-based silver ion sensor using DNA-functionalized gold nanoparticles as a mass amplifier. Nanotechnology. 2017;28(24):245501 This article focuses over designing mass amplifier-based nanosensor by using aptamer specificity to bind $\mathrm{Ag}^{+}$and induce measurable change in resonance frequency.

113. Wu CS, Khaing Oo MK, Fan X. Highly sensitive multiplexed heavy metal detection using quantum-dot-labeled DNAzymes. ACS Nano. 2010;4(10):5897-904.

114. Su YT, Lan GY, Chen WY, Chang HT. Detection of copper ions through recovery of the fluorescence of DNA-templated copper/ silver nanoclusters in the presence of mercaptopropionic acid. Anal Chem. 2010;82(20):8566-72.

115. Guo Z, Zheng Y, Xu H, Zheng B, Qiu W, Liu G. Lateral flow test for visual detection of silver (I) based on cytosine-Ag (I)-cytosine interaction in C-rich oligonucleotides. Microchim Acta. 2017;184(11):4243-50.

116. Lee D, Lee H, Lee G, Kim I, Lee SW, Kim W, et al. Extremely sensitive and wide-range silver ion detection via assessing the integrated surface potential of a DNA-capped gold nanoparticle. Nanotechnology. 2018;30(8):085501.

117. Li S, Cao W, Kumar A, Jin S, Zhao Y, Zhang C, et al. Highly sensitive simultaneous detection of mercury and copper ions by ultrasmall fluorescent DNA-Ag nanoclusters. New J Chem. 2014;38(4):1546-50.

118. Wang HB, Zhang HD, Chen Y, Huang KJ, Liu YM. A label-free and ultrasensitive fluorescent sensor for dopamine detection based on double-stranded DNA templated copper nanoparticles. Sensors Actuators B Chem. 2015;220:146-53.

119. Lin Y, Yin M, Pu F, Ren J, Qu X. DNA-templated silver nanoparticles as a platform for highly sensitive and selective fluorescence turn-on detection of dopamine. Small. 2011;7(11):1557-61.

120.• Enkin N, Sharon E, Golub E, Willner I. Ag nanocluster/DNA hybrids: functional modules for the detection of nitroaromatic and RDX explosives. Nano Lett. 2014;14(8):4918-22 This article shows how explosive pollutant can be detected by designing a pair of donor-acceptor such that pollutant acts as preferable acceptor to induce fluorescence quenching.

121. Peng J, Ling J, Wen QL, Li Y, Cao QE, Huang ZJ, et al. The presence of a single-nucleotide mismatch in linker increases the fluorescence of guanine-enhanced DNA-templated Ag nanoclusters and their application for highly sensitive detection of cyanide. RSC Adv. 2018;8(72):41464-71.

122. Rai PK, Lee SS, Zhang M, Tsang YF, Kim KH. Heavy metals in food crops: health risks, fate, mechanisms, and management. Environ Int. 2019;125:365-85.

123. Liu X, Song Q, Tang Y, Li W, Xu J, Wu J, et al. Human health risk assessment of heavy metals in soil-vegetable system: a multi-medium analysis. Sci Total Environ. 2013;463:530-40.

124. Pazi I, Gonul LT, Kucuksezgin F, Avaz G, Tolun L, Unluoglu A, et al. Potential risk assessment of metals in edible fish species for human consumption from the Eastern Aegean Sea. Mar Pollut Bull. 2017;120(1-2):409-13.

125. Keshavarzi B, Hassanaghaei M, Moore F, Mehr MR, Soltanian S, Lahijanzadeh AR, et al. Heavy metal contamination and health risk assessment in three commercial fish species in the Persian Gulf. Mar Pollut Bull. 2018;129(1):245-52.

126. Rajeshkumar S, Liu Y, Zhang X, Ravikumar B, Bai G, Li X. Studies on seasonal pollution of heavy metals in water, sediment, fish and oyster from the Meiliang Bay of Taihu Lake in China. Chemosphere. 2018;191:626-38.

127. Chen WY, Lan GY, Chang HT. Use of fluorescent DNA-templated gold/silver nanoclusters for the detection of sulfide ions. Anal Chem. 2011;83(24):9450-5.

128. Peng J, Ling J, Zhang XQ, Bai HP, Zheng L, Cao QE, et al. Sensitive detection of mercury and copper ions by fluorescent DNA/Ag nanoclusters in guanine-rich DNA hybridization. Spectrochim Acta A Mol Biomol Spectrosc. 2015;137:1250-7.

129. Mao A, Wei C. Cytosine-rich ssDNA-templated fluorescent silver and copper/silver nanoclusters: optical properties and sensitive detection for mercury (II). Microchim Acta. 2019;186(8):541.

130.• Kim TY, Lim MC, Woo MA, Jun BH. Radial flow assay using gold nanoparticles and rolling circle amplification to detect mercuric ions. Nanomaterials. 2018;8(2):81 This article describes novel method of $\mathrm{Hg}^{2+}$ detection in which $\mathrm{Hg}^{2+}$ block using amplification of AuNPs attached DNA over circular template. The molecular weight of AuNP-DNA formed and its diffusion on membrane depend upon metal ion concentration.

131.• Goud KY, Reddy KK, Satyanarayana M, Kummari S, Gobi KV. A review on recent developments in optical and electrochemical aptamer-based assays for mycotoxins using advanced 
nanomaterials. Microchim Acta. 2020;187(1):29 This article describes in detail designing of DNA nanosensors for the detection of fungal toxin as well as challenges in designing such mycotoxin nanosensor.

132. Majumdar S, Thakur D, Chowdhury D. DNA carbon-nanodots based electrochemical biosensor for detection of mutagenic nitrosamines. ACS Appl Bio Mater. 2020;3(3):1796-803.

133. Baptista PV, Koziol-Montewka M, Paluch-Oles J, Doria G, Franco R. Gold-nanoparticle-probe-based assay for rapid and direct detection of Mycobacterium tuberculosis DNA in clinical samples. Clin Chem. 2006;52(7):1433-4.

134. Talebian S, Wallace GG, Schroeder A, Stellacci F, Conde J. Nanotechnology-based disinfectants and sensors for SARSCoV-2. Nat Nanotechnol. 2020;15(8):618-21.

135. Zhou L, Chandrasekaran AR, Punnoose JA, Bonenfant G, Charles S, Levchenko O, et al. Programmable low-cost DNA-based platform for viral RNA detection. Sci Adv. 2020;39(6):6246.

136. Ali ME, Hashim U, Mustafa S, Che Man YB, Islam KN. Gold 1395 nanoparticle sensor for the visual detection of pork adulteration in 1396 meatball formulation. J Nanomater. 2012;2012: 103607.

137. Houhoula DP, Kouzilou M, Tzogias C, Kyrana V, Sflomos C, Tsaknis J, et al. Effectual gold nanoprobe sensor for screening horse adulteration in meat products. J Food Res. 2017;6(4):34-9.

138. Xu HB, Ye RF, Yang SY, Li R, Yang X. Electrochemical DNA nano-biosensor for the detection of genotoxins in water samples. Chin Chem Lett. 2014;25(1):29-34.

139. Jiang Y, Sun DW, Pu H, Wei Q. Ultrasensitive analysis of kanamycin residue in milk by SERS-based aptasensor. Talanta. 2019;197:151-8.
140. Long F, Zhu A, Shi H, Wang H, Liu J. Rapid on-site/in-situ detection of heavy metal ions in environmental water using a structure-switching DNA optical biosensor. Sci Rep. 2013;3(1):1-7.

141. Daniel SK, Kumar A, Sivasakthi K, Thakur CS. Handheld, lowcost electronic device for rapid, real-time fluorescence-based detection of $\mathrm{Hg}^{2+}$, using aptamer-templated $\mathrm{ZnO}$ quantum dots. Sensors Actuators B Chem. 2019;290:73-8.

142. Environmental monitoring market by product (indoor, outdoor monitors [fixed, portable], sensors, wearables), component (particulate, gas, temperature, noise), sampling method (continuous, active), application (air, water, soil, noise) - global forecast to 2025. ID: 5136091. August 2020. Markets and Markets. https:// www.researchandmarkets.com/reports/5136091/environmentalmonitoring-market-by-product. Accessed on 26 September 2020.

143. Nanosensors market-forecasts from 2018 to 2023. ID: 4479459. March 2018. 97 pages. Knowledge Sourcing Intelligence LLP. https://www.researchandmarkets.com/reports/4479459/ nanosensors-market-forecasts-from-2018-to-2023\#relb 14606856. Accessed on 25 September 2020.

144. Nano biosensors market-growth, trends, and forecast (20202025). https://www.researchandmarkets.com/reports/4591323/ nano-biosensors-market-growth-trends-and\#rela4-4606856. 120 pages, January 2020 ID: 4591323. Accessed on 26 September 2020 .

Publisher's Note Springer Nature remains neutral with regard to jurisdictional claims in published maps and institutional affiliations. 